Cite this: Phys. Chem. Chem. Phys., 2012, 14, 9377-9388

\title{
Structural variability in transition metal oxide clusters: gas phase vibrational spectroscopy of $\mathbf{V}_{\mathbf{3}} \mathbf{O}_{6-8}{ }^{+} \dagger \ddagger \S$
}

\author{
Knut R. Asmis, ${ }^{a b}$ Torsten Wende, ${ }^{a}$ Mathias Brümmer, ${ }^{b}$ Oliver Gause, ${ }^{b}$ \\ Gabriele Santambrogio, ${ }^{a b}$ E. Cristina Stanca-Kaposta, ${ }^{b}$ Jens Döbler, ${ }^{c}$ \\ Andrzej Niedziela ${ }^{c}$ and Joachim Sauer*c
}

\author{
Received 24th January 2012, Accepted 22nd March 2012
}

DOI: $10.1039 / \mathrm{c} 2 \mathrm{cp} 40245 \mathrm{a}$

We present gas phase vibrational spectra of the trinuclear vanadium oxide cations $\mathrm{V}_{3} \mathrm{O}_{6}{ }^{+} \cdot \mathrm{He}_{1-4}$, $\mathrm{V}_{3} \mathrm{O}_{7}{ }^{+} \cdot \mathrm{Ar}_{0,1}$, and $\mathrm{V}_{3} \mathrm{O}_{8}{ }^{+} \cdot \mathrm{Ar}_{0,2}$ between 350 and $1200 \mathrm{~cm}^{-1}$. Cluster structures are assigned based on a comparison of the experimental and simulated IR spectra. The latter are derived from B3LYP/TZVP calculations on energetically low-lying isomers identified in a rigorous search of the respective configurational space, using higher level calculations when necessary. $\mathrm{V}_{3} \mathrm{O}_{7}{ }^{+}$has a cage-like structure of $C_{3 \mathrm{v}}$ symmetry. Removal or addition of an O-atom results in a substantial increase in the number of energetically low-lying structural isomers. $\mathrm{V}_{3} \mathrm{O}_{8}{ }^{+}$also exhibits the cage motif, but with an $\mathrm{O}_{2}$ unit replacing one of the vanadyl oxygen atoms. A chain isomer is found to be most stable for $\mathrm{V}_{3} \mathrm{O}_{6}{ }^{+}$. The binding of the rare gas atoms to $\mathrm{V}_{3} \mathrm{O}_{6-8}{ }^{+}$clusters is found to be strong, up to $55 \mathrm{~kJ} / \mathrm{mol}$ for $\mathrm{Ar}$, and markedly isomer-dependent, resulting in two interesting effects. First, for $\mathrm{V}_{3} \mathrm{O}_{7}{ }^{+} \cdot \mathrm{Ar}$ and $\mathrm{V}_{3} \mathrm{O}_{8}{ }^{+}$. $\mathrm{Ar}$ an energetic reordering of the isomers compared to the bare ion is observed, making the ring motif the most stable one. Second, different isomers bind different number of rare gas atoms. We demonstrate how both effects can be exploited to isolate and assign the contributions from multiple isomers to the vibrational spectrum. The present results exemplify the structural variability of vanadium oxide clusters, in particular, the sensitivity of their structure on small perturbations in their environment.

\section{Introduction}

Due to their structural variability and redox activity vanadium oxides are used in heterogeneous catalysis, ${ }^{1}$ predominantly in selective oxidation processes for the production of olefines. Recently, much effort has been directed towards the production of nanostructured vanadium oxide materials, ${ }^{2}$ with the aim of optimizing their activity and selectivity. However, in most supported transition metal oxide catalysts, neither the size and distribution of the active particles on the support surface,

${ }^{a}$ Fritz-Haber-Institut der Max-Planck-Gesellschaft, Faradayweg 4-6, D-14195 Berlin, Germany. E-mail: asmis@fhi-berlin.mpg.de;

Fax: + 4930 8413-5603; Tel: + 4930 8413-5735

${ }^{b}$ Institut für Experimentalphysik, Freie Universität Berlin, Arnimallee 14, D-14195 Berlin, Germany

${ }^{c}$ Institut für Chemie, Humboldt-Universität Berlin, Unter den Linden 6, D-10099 Berlin, Germany.E-mail: js@chemie.hu-berlin.de; Fax: + 4930 2093-7136; Tel: + 4930 2093-7134

$\dagger$ This article is dedicated to Prof. Dr. Drs. h.c. Ludger Wöste on the occasion of his 65 th birthday.

$\ddagger$ This article is part of the Themed Issue "Structure and reactivity of small particles: From clusters to aerosols."

$\S$ Electronic supplementary information (ESI) available: Computational details for wavefunction based calculations and total energies, as well as additional experimental details and the IRPD spectrum of $\mathrm{V}_{3} \mathrm{O}_{7}{ }^{+} \cdot$ Ne. See DOI: $10.1039 / \mathrm{c} 2 \mathrm{cp} 40245 \mathrm{a}$ nor their structure is sufficiently known. ${ }^{3}$ Studies on size-selected transition metal oxide particles in the gas phase, i.e. in the absence of any interactions with a medium or support, allow for separation of the particle size from support effects, and, thereby lead to a better understanding of the structure-reactivity relationship. ${ }^{4}$ Ultimately, we would like to learn how the gas phase structures differ from those of supported clusters, the structure of bulk oxides and other aggregates such as thin films. ${ }^{5-7}$

The structural characterization of size-selected transition metal oxide clusters in the gas phase remains challenging. ${ }^{8}$ Anion photoelectron spectroscopy has been used to characterize the electronic and structural properties of mono-, di- and polyvanadium oxide anions. ${ }^{9}$ A more detailed structural characterization of gas phase clusters was made possible with the application of infrared photoionization and photodissociation (IRPD) spectroscopy to transition metal oxide clusters. ${ }^{8,10-12}$ IRPD studies on small and medium-sized vanadium oxide cations ${ }^{11-14}$ and anions, ${ }^{7,15,16}$ as well as related studies on niobium ${ }^{17}$ and tantalum $^{18}$ oxide clusters suggested that transition metal oxide clusters exhibit a pronounced structural diversity.

Structure determination with the above-mentioned experimental techniques is generally indirect; it relies on the comparison of experimental with simulated spectra, which are usually derived from quantum chemical calculations for minimum 
energy structures. Currently, quantum chemical methods face two problems. The first is finding the global energy minimum structures, i.e. the most stable isomer. ${ }^{19}$ Even global optimization strategies such as simulated annealing or genetic algorithms cannot guarantee that the global minimum is found. The second is that the level of the quantum chemical approximations that can be applied is not always sufficient to yield the right isomer as the global minimum structure. Most powerful is, hence, a combination of quantum chemical structure predictions with a verification of the structure found by comparing the predicted IR spectra with the observed ones.

Here we study $\mathrm{V}_{3} \mathrm{O}_{7}{ }^{+}$as the smallest polynuclear vanadium oxide cation that shares the closed shell electronic structure and the vanadium +5 oxidation state with supported vanadia particles and bulk $\mathrm{V}_{2} \mathrm{O}_{5}{ }^{6}$ Gas phase experiments ${ }^{20}$ in combination with quantum chemical calculations ${ }^{20,21}$ have produced evidence that $\mathrm{V}_{3} \mathrm{O}_{7}^{+}$abstracts hydrogen from hydrocarbons $\left(\mathrm{C}_{3} \mathrm{H}_{8}\right)$ similarly to vanadia based catalysts in oxidative dehydrogenation reactions. We also examine the oxygen deficient $\mathrm{V}_{3} \mathrm{O}_{6}{ }^{+}$as a possible reaction product (in a complex with $\mathrm{H}_{2} \mathrm{O}$ ) and $\mathrm{V}_{3} \mathrm{O}_{8}{ }^{+}$as species possibly involved in the reoxidation with $\mathrm{O}_{2}{ }^{22}$

We employ two complementary techniques to measure vibrational spectra of the trinuclear vanadium oxide cations: IRPD of (a) cation-rare gas atom complexes ${ }^{23}$ and (b) bare vanadium oxide cations. ${ }^{8}$ This not only allows us to examine, if and how the ion-messenger atom interaction affects the properties of the ion of interests, e.g., shifts vibrational transitions and changes transition intensities, but also, if it is strong enough to change the energetic ordering of structural and electronic isomers. In a recent review article we presented preliminary results for the Ar-tagged clusters $\mathrm{V}_{3} \mathrm{O}_{6}{ }^{+} \cdot \mathrm{Ar}_{2}$ and $\mathrm{V}_{3} \mathrm{O}_{7}{ }^{+} \cdot \mathrm{Ar}^{16}{ }^{16}$ Here, we present the results of a more comprehensive study for $\mathrm{V}_{3} \mathrm{O}_{6-8}{ }^{+}$, including the IRPD spectra of the bare ions, as well as those of clusters with different messenger atoms. We show that for $\mathrm{V}_{3} \mathrm{O}_{6}{ }^{+} \cdot \mathrm{He}$ multiple isomers contribute to the IRPD spectrum. For the Ar complexes of $\mathrm{V}_{3} \mathrm{O}_{7}{ }^{+}$and $\mathrm{V}_{3} \mathrm{O}_{8}{ }^{+}$ring structures are most stable, whereas cage structures are found as global minima for the bare ions. This suggests that the presence of the support and/or the reactant gases may change the active phase structure of supported catalysts.

We first present the IRPD spectra of $\mathrm{V}_{3} \mathrm{O}_{6}{ }^{+} \cdot \mathrm{He}, \mathrm{V}_{3} \mathrm{O}_{7}{ }^{+} \cdot \mathrm{Ar}_{0,1}$, and $\mathrm{V}_{3} \mathrm{O}_{8}{ }^{+} \cdot \mathrm{Ar}_{0,2}$. We then use density functional theory (DFT) to determine possible structures. To find the lowest energy structures we apply a genetic algorithm for global optimization ${ }^{24,25}$ that has successfully been applied to oxide clusters before. ${ }^{15,24,26}$ Finally, experimental vibrational spectra are assigned to structures by comparison with simulated spectra, based on scaled harmonic vibrational frequencies and intensities. ${ }^{16}$

\section{Experiment}

The experiments on the bare metal oxide cations were carried out using an ion-trap tandem quadrupole mass spectrometer ${ }^{11}$ temporarily installed at the "Free Electron Laser for Infrared eXperiments" (FELIX) facility ${ }^{27}$ at the FOM Institute Rijnhuizen (The Netherlands). Briefly, a pulsed beam of vanadium oxide cations is prepared by laser vaporization, collimated in a gas-filled radio frequency (RF) decapole ion guide and then guided into a RF quadrupole mass filter.
Mass-selected cluster ions are guided into a cooled, He gasfilled ( $\sim 0.02$ mbar), RF hexadecapole ion trap, where they are accumulated and thermalized close to the ambient temperature $(15 \mathrm{~K})$ through many collisions with the buffer gas.

IRPD spectra are obtained by photoexcitation of the trapped ions in the ion trap with pulsed radiation from FELIX, operated at $5 \mathrm{~Hz}$ with a bandwidth of $\sim 0.25 \%$ RMS of the central wavelength and pulse energies up to $50 \mathrm{~mJ}$. After FELIX fires, all ions are extracted and the mass-selected ion yield is monitored using a second RF quadrupole mass filter. This cycle is repeated multiple times ( 3 to 10 times for the present experiments) and then FELIX is set to the next wavelength.

The experiments on the rare gas-tagged vanadium oxide cations were performed on a newer, improved version of this instrument, which is described elsewhere. ${ }^{28}$ It typically yields IPRD spectra with a superior signal/noise ratio (compared to the instrument described above), because it differs in two aspects. (a) Better overlap between the ion packet and the laser pulse is achieved by irradiating the focused ion packet after extraction from the ion trap. (b) For each laser shot a complete mass spectrum is measured, increasing the duty cycle significantly. This is achieved by replacing the hexadecapole ion trap and the subsequent quadrupole mass filter by a ring electrode trap and a linear time-of-flight (TOF) mass spectrometer. IRPD spectra are recorded by monitoring all ion intensities simultaneously as the laser wavelength is scanned. With this version of the machine, FELIX is typically operated at $10 \mathrm{~Hz}$ and the measurement cycle is repeated 50-70 times per wavelength step. The photodissociation cross sections $\sigma$ is determined from the normalized parent ion yield $I(\nu)$ and the frequency dependent laser power $P(\nu)$ using $\sigma=-\ln [I(\nu)] / P(\nu)$ (see ESI§ for details).

The messenger-tagged vanadium oxide cations $\mathrm{V}_{3} \mathrm{O}_{6-8}{ }^{+} \cdot \mathrm{M}_{n}$ are produced by three-body association ${ }^{13,26,29}$ inside the gas-filled ion trap, starting out from the mass-selected bare ions. Ideally, $\mathrm{He}$ atoms are used as a messenger $\mathrm{M}$, as they exert the smallest perturbation on the structure of the ion. While $\mathrm{V}_{3} \mathrm{O}_{6}{ }^{+}$is found to bind $\mathrm{He}$ quite readily under our experimental conditions, no He-complex formation was observed for the $\mathrm{V}_{3} \mathrm{O}_{7}{ }^{+}$and $\mathrm{V}_{3} \mathrm{O}_{8}{ }^{+}$, even at the lowest trap temperature. Therefore, larger, more polarisable rare gas atoms $(\mathrm{M}=\mathrm{Ne}$ and $\mathrm{Ar})$ were used to tag these ions, by adding traces of the respective rare gas to the $\mathrm{He}$ buffer gas. The use of these heavier rare gases requires higher trap temperatures (Ne: $20 \mathrm{~K}$, Ar: $50 \mathrm{~K}$ ) to avoid condensation on the ion trap surfaces. Under typical operating conditions often a distribution of messenger complexes is produced, e.g., $n=1-4$ for $\mathrm{V}_{3} \mathrm{O}_{6}{ }^{+} \cdot \mathrm{He}_{n}$ or $n=1-2$ for $\mathrm{V}_{3} \mathrm{O}_{8}{ }^{+} \cdot \mathrm{Ar}_{n}$. Note, all of the formed complexes $(n=1, n=2, \cdots)$ are irradiated by the laser pulse, may dissociate, and contribute to the ion yield for the corresponding mass channel (see ESI§ for details). For the measurements on the messenger-tagged species narrower bandwidth, lower pulse energy laser pulses were used.

\section{Computational methods}

The DFT calculations use the TURBOMOLE program. ${ }^{30}$ The B3LYP hybrid functional ${ }^{31}$ is employed. The TZVP basis sets applied are the triple-zeta valence basis sets developed by Ahlrichs and co-workers ${ }^{32}$ augmented by polarization functions, a d-set for oxygen and a p-set for vanadium, ${ }^{33}[5 \mathrm{~s}, 3 \mathrm{p}, 1 \mathrm{~d}]$ and 
[6s,4p,3d] for O and V, respectively. Structure optimizations use tight convergence criteria, Cartesian gradients smaller than $1 \times 10^{-4}$ Hartree Bohr $^{-1}$ and energy change smaller than $1 \times 10^{-6}$ Hartree, see ESI§ for total energies. The SCF convergence criterion is $1 \times 10^{-7}$ Hartree for the energy and $1 \times 10^{-7}$ a.u. for the root mean square of the density. Harmonic vibrational frequencies are obtained from second analytic derivatives. ${ }^{34}$ It is known that B3LYP vibrational frequencies are systematically too large (see, e.g., ref. 35) and, therefore, agreement with observed frequencies can be improved by scaling, which accounts for neglected anharmonicities as well as systematic errors of the calculated harmonic force constants. We use scaling parameters that we determined for small vanadium oxide cluster cations ${ }^{36}$ and that we applied successfully before for vanadium oxide cluster anions. ${ }^{7,15}$ Vanadyl modes are scaled by 0.9167 , peroxo and superoxo modes by 0.9429 and all $\mathrm{V}-\mathrm{O}-\mathrm{V}$ modes by 0.9832 . These values fall into the known ranges for the B3LYP functional. ${ }^{35}$

The global optimizations use an implementation ${ }^{19}$ of the genetic algorithm that has successfully been applied before. ${ }^{24}$ A population of 30 structures has been used. In each of the 50 generations 15 child structures have been optimized by B3LYP using the smaller SVP basis set. The lowest energy structures emerging have been locally re-optimized with B3LYP/TZVP.

For some of the calculations, specifically for the binding energies of the vanadium oxide cation-rare gas complexes and the potential energy surfaces for the cage-ring conversion, a semiempirical $1 / r^{6}$ dispersion term as parameterized by Grimme ${ }^{37}$ has been added to the B3LYP functional. This typically increases the binding energies of the rare gas atoms, e.g. by 5 to $10 \mathrm{~kJ} / \mathrm{mol}$ for values between 10 and $50 \mathrm{~kJ} / \mathrm{mol}$ for the Ar complexes. We will refer to these results as $\mathrm{B} 3 \mathrm{LYP}+\mathrm{D}$.

For $\mathrm{V}_{3} \mathrm{O}_{6}{ }^{+}$and for $\mathrm{V}_{3} \mathrm{O}_{7}{ }^{+}$single point $\operatorname{CCSD}(\mathrm{T})$ calculations were performed with Turbomole 6.3.1 at the B3LYP + D structures. ${ }^{38}$ They use a ROHF wavefunction as reference and the $[5 s, 3 p, 2 d, 1 f]$ and $[6 s, 4 p, 4 d, 1 f]$ basis sets of Weigend and Ahlrichs for $\mathrm{O}$ and $\mathrm{V}$, respectively, ${ }^{39}$ named "def2"-TZVP in the Turbomole library. Here we call them "TZVP-df" because they differ from the TZVP basis set used for B3LYP calculations ("def"-TZVP) by additional $\mathrm{d}$ and $\mathrm{f}$ functions.

For $\mathrm{V}_{3} \mathrm{O}_{8}{ }^{+}$single point $\mathrm{CCSD}(\mathrm{T})$ and CAS-PT2 calculations were performed with the TZVP basis set with Molpro, ${ }^{40}$ using structures optimized at the B3LYP/TZVP level. The CAS-PT2 calculations used an active space comprised of the p-orbitals of the $\mathrm{O}_{2}$ moiety.

\section{Results}

In this section, we first present the experimental results obtained for the bare ions, $\mathrm{V}_{3} \mathrm{O}_{7}{ }^{+}$and $\mathrm{V}_{3} \mathrm{O}_{8}{ }^{+}$, followed by the results for the messenger-tagged ions $\mathrm{V}_{3} \mathrm{O}_{6}{ }^{+} \cdot \mathrm{He}, \mathrm{V}_{3} \mathrm{O}_{7}{ }^{+}$. $\mathrm{Ar}$, and $\mathrm{V}_{3} \mathrm{O}_{8}{ }^{+} \cdot \mathrm{Ar}_{2}$. We then discuss the structures, energies and vibrational spectra of the relevant isomers obtained from electronic structure calculations and finally combine these two sets of results in the assignment of the measured IRPD spectra.

\subsection{IRPD spectra}

IRPD of bare $\mathrm{V}_{3} \mathrm{O}_{7}{ }^{+}$results in the formation of two fragment ions: $\mathrm{VO}_{2}{ }^{+}\left(\mathrm{V}_{2} \mathrm{O}_{5}\right.$ loss $)$ and $\mathrm{V}_{3} \mathrm{O}_{6}{ }^{+}$(O-atom loss). Of these two competing dissociation channels, $\mathrm{V}_{2} \mathrm{O}_{5}$ loss is roughly 25 times more efficient with both channels giving rise to similar IRPD spectra. In contrast, formation of $\mathrm{V}_{3} \mathrm{O}_{6}{ }^{+}\left(\mathrm{O}_{2}\right.$ or $2 \mathrm{O}$ loss) is the dominant fragment ion observed for the IRPD of $\mathrm{V}_{3} \mathrm{O}_{8}{ }^{+}$. No photodissociation signal is observed upon irradiation of bare $\mathrm{V}_{3} \mathrm{O}_{6}{ }^{+}$ions, the smallest cluster studied here, suggesting a considerably higher dissociation energy and/or a lower density of states. IRPD of the messenger-tagged ions, on the other hand, requires considerably less energy and FELIX was attenuated such that only the rare gas loss channel(s) was (were) observed in these experiments.

The IRPD spectra of $\mathrm{V}_{3} \mathrm{O}_{7}{ }^{+}$and $\mathrm{V}_{3} \mathrm{O}_{8}{ }^{+}$are shown in Fig. 1 . The observed bands are labelled $b_{1}-b_{5}$ and $d_{1}-d_{8}$, respectively, and their positions are listed in Table 1 . The $\mathrm{V}_{3} \mathrm{O}_{7}{ }^{+}$spectrum exhibits three main bands, one in the $\mathrm{V}=\mathrm{O}\left(\mathrm{b}_{2}\right)$ and two in the $\mathrm{V}-\mathrm{O}-\mathrm{V}$ stretching region $\left(\mathrm{b}_{3}, \mathrm{~b}_{4}\right)$. The IRPD signal observed for $\mathrm{V}_{3} \mathrm{O}_{8}{ }^{+}$extends over a similar spectral range as for $\mathrm{V}_{3} \mathrm{O}_{7}{ }^{+}$, but with different relative intensities, suggesting similar structures for both clusters, with a single exception. A weak, but characteristic band is observed at $994 \mathrm{~cm}^{-1}\left(\mathrm{~d}_{2}\right)$ in the $\mathrm{V}_{3} \mathrm{O}_{8}{ }^{+}$ spectrum, which is absent from the $\mathrm{V}_{3} \mathrm{O}_{7}{ }^{+}$spectrum. Since $\mathrm{V}=\mathrm{O}$ vibrational modes in cations are typically found above

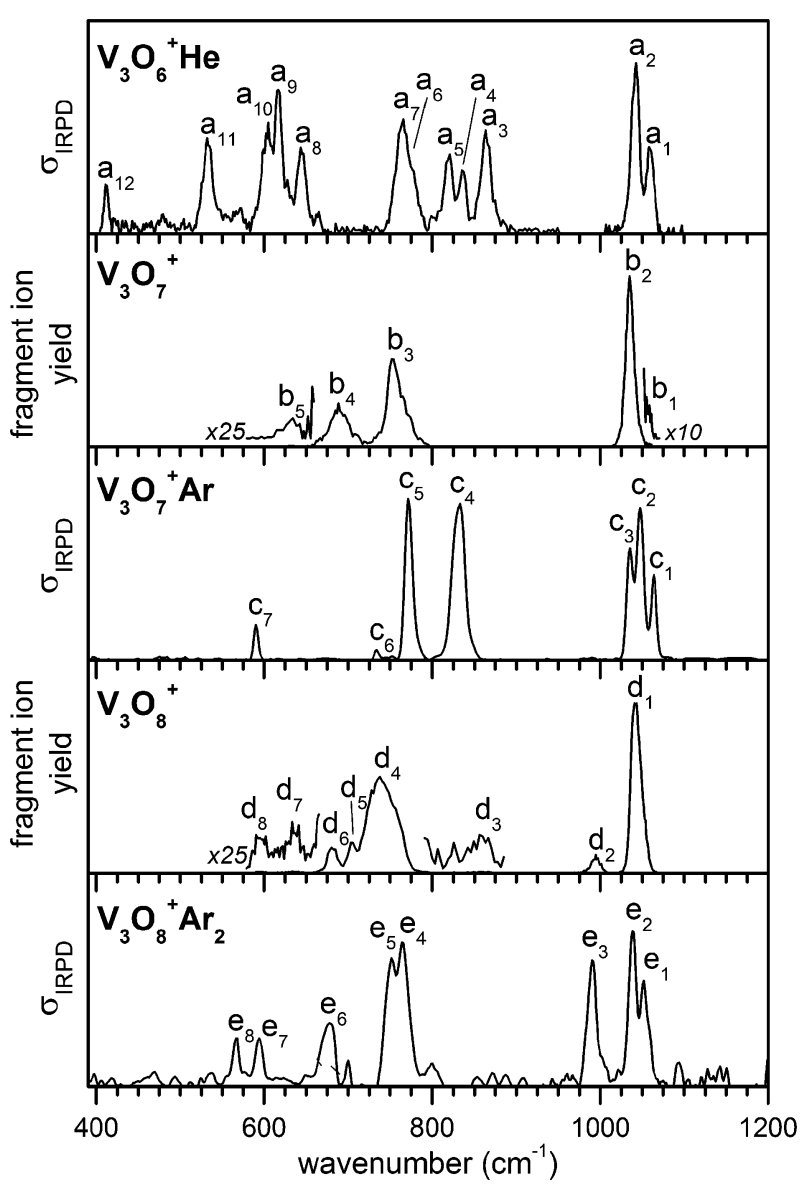

Fig. 1 Experimental IRPD spectra of $\mathrm{V}_{3} \mathrm{O}_{6}{ }^{+} \cdot \mathrm{He}, \mathrm{V}_{3} \mathrm{O}_{7}{ }^{+}, \mathrm{V}_{3} \mathrm{O}_{7}{ }^{+} \cdot \mathrm{Ar}$, $\mathrm{V}_{3} \mathrm{O}_{8}{ }^{+}$, and $\mathrm{V}_{3} \mathrm{O}_{8}{ }^{+} \cdot \mathrm{Ar}_{2}$ in the region from 390 to $1200 \mathrm{~cm}^{-1}$. For the bare ions the yield of the dominant fragment ion, $\mathrm{VO}_{2}{ }^{+}$for $\mathrm{V}_{3} \mathrm{O}_{7}{ }^{+}$ and $\mathrm{V}_{3} \mathrm{O}_{6}{ }^{+}$for $\mathrm{V}_{3} \mathrm{O}_{8}{ }^{+}$, respectively, and for the rare gas complexes the IRPD cross section is plotted (see ESI§ for details). Peak positions of features labelled with indexed letters are listed in Table 1. 
Table 1 Band positions and assignments of the IRPD spectra shown in Fig. 1 and Fig. 11

\begin{tabular}{lll}
\hline System & Assign & Band position (in cm $\left.{ }^{-1}\right)$ and label \\
\hline $\mathrm{V}_{3} \mathrm{O}_{6}{ }^{+} \cdot \mathrm{He}^{a}$ & $\mathrm{~V}=\mathrm{O}$ & $1058\left(\mathrm{a}_{1}\right), 1043\left(\mathrm{a}_{2}\right)$ \\
& $\mathrm{O}-\mathrm{V}-\mathrm{O}$ & $863\left(\mathrm{a}_{3}\right), 835\left(\mathrm{a}_{4}\right), 821\left(\mathrm{a}_{5}\right), 776\left(\mathrm{a}_{6}\right)$, \\
& & $766\left(\mathrm{a}_{7}\right), 643\left(\mathrm{a}_{8}\right), 617\left(\mathrm{a}_{9}\right), 605\left(\mathrm{a}_{10}\right)$, \\
$\mathrm{V}_{3} \mathrm{O}_{6}{ }^{+} \cdot \mathrm{He}_{4}{ }^{a}$ & $\mathrm{~V}=\mathrm{O}$ & $532\left(\mathrm{a}_{10}\right), 411\left(\mathrm{a}_{11}\right)$ \\
& $\mathrm{O}-\mathrm{V}-\mathrm{O}$ & $837\left(\mathrm{a}_{2}^{\prime \prime}\right), 782\left(\mathrm{a}_{6}^{\prime \prime}\right), 614\left(\mathrm{a}_{9}^{\prime \prime}\right), 413\left(\mathrm{a}_{12}^{\prime \prime}\right)$ \\
$\mathrm{He}_{1}-\mathrm{He}_{2}{ }^{a}$ & $\mathrm{~V}=\mathrm{O}$ & $1060\left(\mathrm{a}_{1}^{\prime}\right), 1038\left(\mathrm{a}_{2}^{\prime}\right)$ \\
& $\mathrm{O}-\mathrm{V}-\mathrm{O}$ & $863\left(\mathrm{a}_{3}^{\prime}\right), 819\left(\mathrm{a}_{5}^{\prime}\right), 766\left(\mathrm{a}_{7}^{\prime}\right), 643\left(\mathrm{a}_{8}^{\prime}\right)$, \\
& & $602\left(\mathrm{a}_{10}^{\prime}\right), 534\left(\mathrm{a}_{11}^{\prime}\right)$ \\
$\mathrm{V}_{3} \mathrm{O}_{7}{ }^{+}$ & $\mathrm{V}=\mathrm{O}$ & $1058\left(\mathrm{~b}_{1}\right), 1035\left(\mathrm{~b}_{2}\right)$ \\
& $\mathrm{O}-\mathrm{V}-\mathrm{O}$ & $753\left(\mathrm{~b}_{3}\right), 689\left(\mathrm{~b}_{4}\right), 634\left(\mathrm{~b}_{5}\right)$ \\
$\mathrm{V}_{3} \mathrm{O}_{7}{ }^{+} \cdot \mathrm{Ar}$ & $\mathrm{V}=\mathrm{O}$ & $1064\left(\mathrm{c}_{1}\right), 1047\left(\mathrm{c}_{2}\right), 1035\left(\mathrm{c}_{3}\right)$ \\
& $\mathrm{O}-\mathrm{V}-\mathrm{O}$ & $833\left(\mathrm{c}_{4}\right), 771\left(\mathrm{c}_{5}\right), 734\left(\mathrm{c}_{6}\right), 590\left(\mathrm{c}_{7}\right)$ \\
$\mathrm{V}_{3} \mathrm{O}_{8}{ }^{+}$ & $\mathrm{V}=\mathrm{O}$ & $1042\left(\mathrm{~d}_{1}\right)$ \\
& $\mathrm{O}-\mathrm{O}$ & $994\left(\mathrm{~d}_{2}\right)$ \\
& $\mathrm{O}-\mathrm{V}-\mathrm{O}$ & $856\left(\mathrm{~d}_{3}\right), 738\left(\mathrm{~d}_{4}\right), 703\left(\mathrm{~d}_{5}\right), 681\left(\mathrm{~d}_{6}\right)$, \\
& & $637\left(\mathrm{~d}_{7}\right), 595\left(\mathrm{~d}_{8}\right)$ \\
$\mathrm{V}_{3} \mathrm{O}_{8}{ }^{+} \cdot \mathrm{Ar}_{2}$ & $\mathrm{~V}=\mathrm{O}$ & $1052\left(\mathrm{e}_{1}\right), 1039\left(\mathrm{e}_{2}\right)$ \\
& $\mathrm{O}-\mathrm{O}$ & $991\left(\mathrm{e}_{3}\right)$ \\
& $\mathrm{O}-\mathrm{V}-\mathrm{O}$ & $765\left(\mathrm{e}_{4}\right), 752\left(\mathrm{e}_{5}\right), 678\left(\mathrm{e}_{6}\right), 594\left(\mathrm{e}_{7}\right)$, \\
& & $567\left(\mathrm{e}_{8}\right)$
\end{tabular}

${ }^{a}$ See ESI for details on how the IRPD spectra are obtained. $\mathrm{He}_{1}-\mathrm{He}_{2}$ refers to the difference spectrum in Fig. 11.

$1000 \mathrm{~cm}^{-1}$ (and $\mathrm{V}-\mathrm{O}-\mathrm{V}$ modes below $875 \mathrm{~cm}^{-1}$ ) ${ }^{16}$ we tentatively assign $\mathrm{d}_{2}$ to the excitation of an $\mathrm{O}-\mathrm{O}$ stretching vibration in a peroxo group, suggesting $\mathrm{O}_{2}$-loss (instead of 2O) as the dominant IRPD channel for $\mathrm{V}_{3} \mathrm{O}_{8}{ }^{+}$. Both spectra contain some additional, weaker features, which are discussed in Section 4.3.

The IRPD spectra of $\mathrm{V}_{3} \mathrm{O}_{6-8}{ }^{+}$-rare gas complexes, also shown in Fig. 1, reveal more structure. For example, three vanadyl bands are resolved for $\mathrm{V}_{3} \mathrm{O}_{7}{ }^{+} \cdot \mathrm{Ar}\left(\mathrm{c}_{1}-\mathrm{c}_{3}\right)$ and two for $\mathrm{V}_{3} \mathrm{O}_{8}{ }^{+} \cdot \mathrm{Ar}_{2}\left(\mathrm{e}_{1}, \mathrm{e}_{2}\right)$, compared to just a single band in the spectra of $\mathrm{V}_{3} \mathrm{O}_{7}{ }^{+}\left(\mathrm{b}_{2}\right)$ and $\mathrm{V}_{3} \mathrm{O}_{8}{ }^{+}\left(\mathrm{d}_{1}\right)$. The narrower IRPD bands are in part a result of the lower energy, narrower bandwidth FELIX laser pulses used to obtain these spectra. The threshold for breaking the ion-rare gas bonds is significantly lower than breaking covalent bonds in the bare ions. Consequently, fewer IR photons need to be absorbed to induce dissociation, leading to IRPD spectra that typically look more similar to linear absorption spectra (see ref. 8, 12, 41 for details concerning the multiple photon excitation mechanism, the messenger technique and their effects on the IRPD spectrum). For example, the lowest predicted dissociation energies for $\mathrm{V}_{3} \mathrm{O}_{7}{ }^{+}, \mathrm{V}_{3} \mathrm{O}_{7}{ }^{+} \cdot \mathrm{Ar}$, and $\mathrm{V}_{3} \mathrm{O}_{7}{ }^{+} \cdot \mathrm{Ne}$ are 165 , 55 , and $21 \mathrm{~kJ} / \mathrm{mol}$, respectively (see Table 2). Photodissociation in the $390-1200 \mathrm{~cm}^{-1}$ range thus requires multiple photons in all three cases, but significantly less for the Ar complex and even fewer for the Ne complex compared to the bare ion. In part, the additional structure can also be attributed to the mere presence of the messenger atom, which lowers the symmetry and consequently relaxing the selection rules, as previously shown for $\mathrm{V}_{3} \mathrm{O}_{6}{ }^{+} \cdot \mathrm{Ar}_{2} \cdot{ }^{16}$ However, the spectrum of $\mathrm{V}_{3} \mathrm{O}_{7}{ }^{+}$.Ar, which agrees reasonably well with the previously published one, ${ }^{16}$ also shows absorption in different parts of the IR spectrum compared to the spectrum of bare $\mathrm{V}_{3} \mathrm{O}_{7}{ }^{+}$, suggesting that the two experiments (IRPD of bare ion vs. messenger-tagged ion) actually probe different structural isomers.
Table 2 Relative stability of $\mathrm{V}_{3} \mathrm{O}_{7}{ }^{+}$isomers and their $\mathrm{Ne}$ and $\mathrm{Ar}$ complexes, $E(\mathrm{~kJ} / \mathrm{mol})$, predicted by $\mathrm{B} 3 \mathrm{LYP}+\mathrm{D} / \mathrm{TZVP} . \Delta E(\mathrm{~kJ} / \mathrm{mol})$ is the binding energy of $\mathrm{Ne}, \mathrm{Ar}$ atoms on $\mathrm{V}_{3} \mathrm{O}_{7}{ }^{+}$, and $R$ the $\mathrm{Ne} / \mathrm{Ar} \cdots \mathrm{V}$ distance $(\mathrm{pm})$. B3LYP results without dispersion are given in parenthesis

\begin{tabular}{lllll}
\hline Isomer & Cage & Ring & TS cage-ring & Chain \\
\hline $\mathrm{V}_{3} \mathrm{O}_{7}{ }^{+}$ & $C_{3 \mathrm{v}^{-}}{ }^{1} A_{1}$ & $C_{\mathrm{s}^{-}}{ }^{1} A^{\prime}$ & $C_{\mathrm{s}^{-}}{ }^{1} A^{\prime}$ & $C_{\mathrm{s}^{-}}{ }^{3} A^{\prime \prime}$ \\
$E$ & $0.0(0.0)^{a}$ & $7.1(17.4)$ & $25.8(30.1)$ & $-(118.9)$ \\
$\mathrm{V}_{3} \mathrm{O}_{7}{ }^{+} \cdot \mathrm{Ne}^{b}$ & $C_{\mathrm{s}^{-}}{ }^{-} A^{\prime}$ & $C_{\mathrm{s}^{-}}{ }^{-1} A^{\prime}$ & $C_{\mathrm{s}^{-}}{ }^{-} A^{\prime}$ & \\
$R$ & 276 & 233 & 255 & \\
$\Delta E$ & 10.1 & 20.5 & 3.6 & \\
$E$ & 3.4 & 0.0 & 35.7 & \\
$\mathrm{~V}_{3} \mathrm{O}_{7}{ }^{+} \cdot \mathrm{Ar}^{b}$ & $C_{\mathrm{s}^{-}}{ }^{1} A^{\prime}$ & $C_{\mathrm{s}^{-}}{ }^{1} A^{\prime}$ & $C_{\mathrm{s}}{ }^{-} A^{\prime}$ & \\
$R$ & $252(277)$ & $252(253)$ & $255(255)$ & \\
$\Delta E$ & $23.1(15.5)$ & $54.7(50.1)$ & $34.3(28.7)$ & \\
$E$ & $24.6(17.1)$ & $0.0(0.0)$ & $39.2(34.1)$ &
\end{tabular}

${ }^{a}$ Binding energy with respect to $\mathrm{V}_{2} \mathrm{O}_{5}$ and $\mathrm{VO}_{2}{ }^{+}$is $4.95 \mathrm{eV}$; wrt $\mathrm{V}_{3} \mathrm{O}_{6}{ }^{+}$and $\frac{1}{2} \mathrm{O}_{2}$ is $165.0 \mathrm{~kJ} / \mathrm{mol} .{ }^{b}$ Electronic state is $C_{\mathrm{s}^{-}}{ }^{1} A^{\prime}$ for all isomers and the transition structure (TS).

In more detail, bands $\mathrm{c}_{1}, \mathrm{c}_{4}$, and $\mathrm{c}_{7}$ in the $\mathrm{V}_{3} \mathrm{O}_{7}{ }^{+}$. Ar lie in regions, where little to no photodissociation is observed for bare $\mathrm{V}_{3} \mathrm{O}_{7}{ }^{+}$and, vice versa, $\mathrm{V}_{3} \mathrm{O}_{7}{ }^{+}$. Ar does not absorb in the region of band $\mathrm{b}_{4}$ of bare $\mathrm{V}_{3} \mathrm{O}_{7}{ }^{+}$.

For $\mathrm{V}_{3} \mathrm{O}_{6}{ }^{+} \cdot \mathrm{He}$, we find evidence for (at least) two isomers contributing to the IRPD spectrum. The spectra of $\mathrm{V}_{3} \mathrm{O}_{6}{ }^{+}$. $\mathrm{He}_{n}$ with $n>1$ (see ESI§) reveal a much simpler absorption pattern than the $n=1$ spectrum shown in Fig. 1. In particular, the features corresponding to peaks $\mathrm{a}_{1}, \mathrm{a}_{3}, \mathrm{a}_{5}, \mathrm{a}_{7}, \mathrm{a}_{8}, \mathrm{a}_{10}$, and $a_{11}$ are either much weaker or completely missing from the $n \geq 2$ spectra, suggesting that only one of the isomers present binds more than one He atom efficiently. Consequently, the IRPD spectrum of this isomer is predominantly reflected in the spectra of the $n=2, n=3$, and $n=4$ complexes. The IR spectrum of the other isomer can also be isolated, for example, by subtraction (see Section 4.3).

\subsection{Calculated structures and energies for $\mathrm{V}_{3} \mathrm{O}_{6-8}{ }^{+}$and their rare gas complexes}

Fig. 2-4 show the optimized B3LYP/TZVP structures and Tables 2-4 list the relative energies of relevant $\mathrm{V}_{3} \mathrm{O}_{6-8}{ }^{+}$ isomers and their rare gas complexes.

$\mathbf{V}_{3} \mathbf{O}_{7}{ }^{+}$. Adopting the ionic picture, in $\mathrm{V}_{3} \mathrm{O}_{7}{ }^{+}$, vanadium has donated all valence electrons to oxygen, forming three $\mathrm{V}^{5+}$ ions and seven $\mathrm{O}^{2-}$ ions, which results in a total charge of +1 and a closed shell electronic structure. $\mathrm{V}_{3} \mathrm{O}_{7}{ }^{+}$is the smallest polynuclear closed-shell $\mathrm{V}^{5+}$ ion. Its $C_{3 \mathrm{v}}$ structure, reported before, ${ }^{6,42}$ is formed by a six-membered ring that consists of three equivalent $\mathrm{V}^{5+}$ and $\mathrm{O}^{2-}$ ions. Three exocyclic $\mathrm{O}^{2-}$ ions are attached to each $\mathrm{V}^{5+}$ ion and one central $\mathrm{O}^{2-}$ ion coordinates to all three $\mathrm{V}^{5+}$ ions (cage structure in Fig. 2). A ring structure with only two equivalent $\mathrm{V}^{5+}$ ions in $\mathrm{O}=\mathrm{V}(\mathrm{O}-)_{3}$ coordination and the total charge localized at the $\mathrm{O}=\mathrm{V}^{+}(\mathrm{O}-)_{2}$ site is $17.4 \mathrm{~kJ} / \mathrm{mol}$ less stable (see Table 2 and Fig. 2), but becomes favourable, when an Ar atom or a reaction partner $\left(\mathrm{C}_{3} \mathrm{H}_{8}\right.$, see ref. 21$)$ binds to the site with the localized positive charge. For the bare $\mathrm{V}_{3} \mathrm{O}_{7}{ }^{+}$ion, dispersion stabilizes the ring structure relative to the cage structure. The cage structure remains the most stable one, which is confirmed by B3LYP and CCSD(T) calculations for the larger, TZVP-df, basis set. 


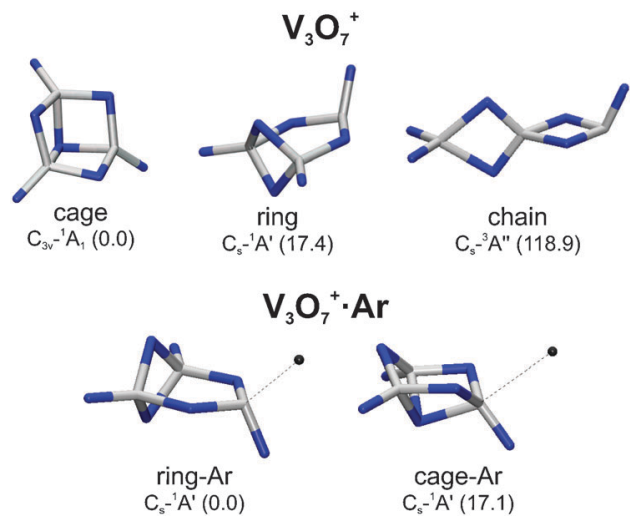

Fig. 2 B3LYP/TZVP structures (vanadium: grey, oxygen: blue, argon: black) and relative energies (in $\mathrm{kJ} / \mathrm{mol}$ ) of relevant $\mathrm{V}_{3} \mathrm{O}_{7}{ }^{+}$ and $\mathrm{V}_{3} \mathrm{O}_{7}{ }^{+} \cdot \mathrm{Ar}$ isomers.
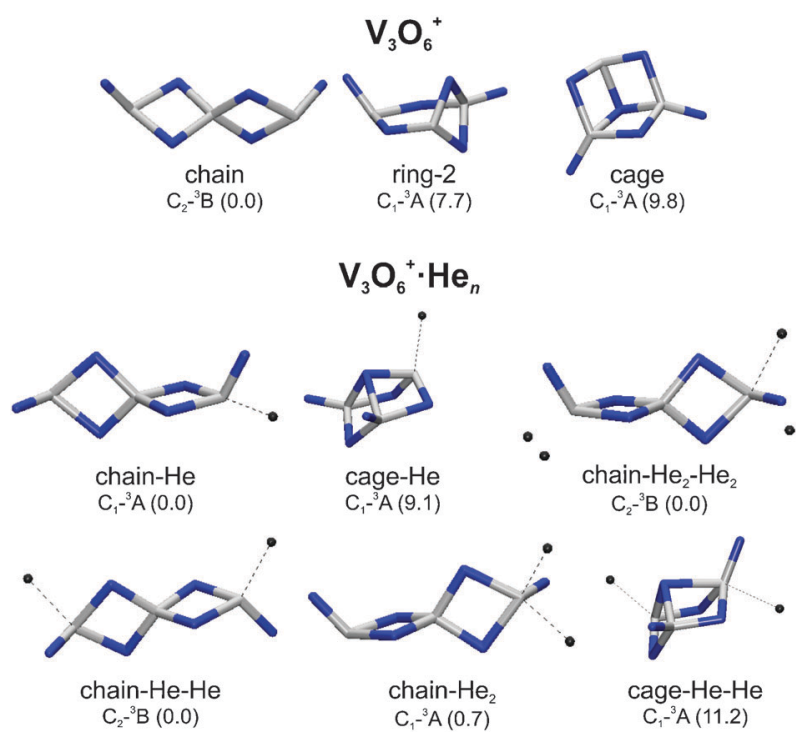

Fig. 3 B3LYP/TZVP structures (vanadium: grey, oxygen: blue, helium: black) and relative energies (in $\mathrm{kJ} / \mathrm{mol}$, see Table 6) of relevant $\mathrm{V}_{3} \mathrm{O}_{6}{ }^{+}$and $\mathrm{V}_{3} \mathrm{O}_{6}{ }^{+} \cdot \mathrm{He}_{n}$ isomers with $n=1,2,4$.

B3LYP/TZVP-df, B3LYP/TZVP-df + D and CCSD(T)/TZVP-df yield the ring structure 25,14 and $27 \mathrm{~kJ} / \mathrm{mol}$ less stable than the cage structure.

$\mathbf{V}_{3} \mathbf{O}_{6}{ }^{+}$. Compared to $\mathrm{V}_{3} \mathrm{O}_{7}{ }^{+}$one $\mathrm{O}$ atom is missing and two electrons are left in vanadium $\mathrm{d}$ states in $\mathrm{V}_{3} \mathrm{O}_{6}{ }^{+}$resulting in one $\mathrm{V}^{5+}$ and two $\mathrm{V}^{4+}$ sites. Hence, structures with threefold symmetry are not expected for $\mathrm{V}_{3} \mathrm{O}_{6}{ }^{+}$. The chain structure has a central $\mathrm{V}^{5+}$ ion in $\mathrm{V}(\mathrm{O}-)_{4}$ coordination, and $\mathrm{V}\left(\mathrm{d}^{1}\right)^{4+}$ ions in terminal $\mathrm{O}=\mathrm{V}(-\mathrm{O})_{2}$ groups (Fig. 3). The d electrons on the terminal $\mathrm{V}$ sites interact weakly and form a triplet ground state which is almost degenerate with the open shell singlet state. In the other two low energy isomers, ring-2 and cage, all three $\mathrm{V}$ sites are non-equivalent. The ring-3up structure (see ESI§) with two $\mathrm{V}\left(\mathrm{d}^{1}\right)^{4+}$ ions in $(-\mathrm{O})_{2} \mathrm{~V}=\mathrm{O}$ groups and one $\mathrm{V}^{5+}$ ion in $\mathrm{O}=\mathrm{V}(\mathrm{O}-)_{2}$ coordination reported in early studies ${ }^{42}$ is $62 \mathrm{~kJ} / \mathrm{mol}$ less stable than the global minimum structure (B3LYP/TZVP).

DFT does not seem to be accurate enough to reliably predict the relative energies of the cage, chain and ring- 2 structures.

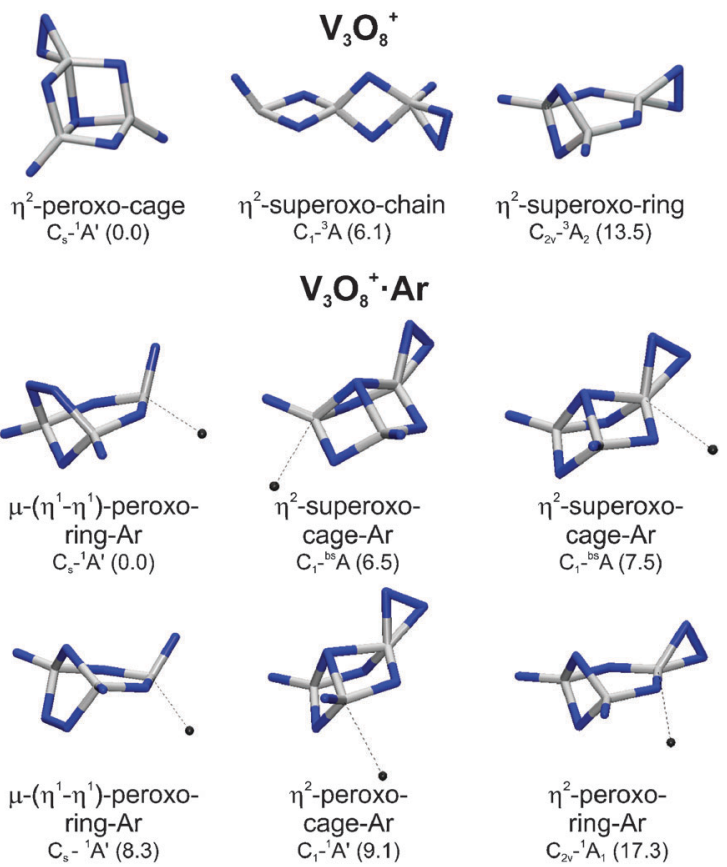

Fig. 4 B3LYP/TZVP structures (vanadium: grey, oxygen: blue, argon: black) and relative energies (in $\mathrm{kJ} / \mathrm{mol}$ ) of relevant $\mathrm{V}_{3} \mathrm{O}_{8}{ }^{+}$ and $\mathrm{V}_{3} \mathrm{O}_{8}{ }^{+} \cdot \mathrm{Ar}$ isomers.

Whereas B3LYP yields the chain structure as most stable, $\mathrm{B} 3 \mathrm{LYP}+\mathrm{D}$ gives preference for the ring-2 structure (Table 3, B3LYP/TZVP). This does not change when the larger TZVP-df basis set is applied. In contrast, $\operatorname{CCSD}(\mathrm{T}) / \mathrm{TZVP}-\mathrm{df}$ calculations favour the cage structure over the chain $(+7 \mathrm{~kJ} / \mathrm{mol})$ and ring-2 $(+17 \mathrm{~kJ} / \mathrm{mol})$ isomers. There is no guarantee that $\operatorname{CCSD}(\mathrm{T})$ is right, but below we will show that the $\operatorname{CCSD}(\mathrm{T})$ stability sequence leads to a consistent interpretation of the observed spectra.

$\mathbf{V}_{3} \mathbf{O}_{\mathbf{8}}{ }^{+}$. Most $\mathrm{V}_{3} \mathrm{O}_{8}{ }^{+}$structures can be generated from $\mathrm{V}_{3} \mathrm{O}_{7}{ }^{+}$structures by replacing an $\mathrm{O}^{2-}$ ion by a peroxo, $\mathrm{O}_{2}{ }^{2-}$ ion, which leaves all three vanadium ions in the highest oxidation state, $\mathrm{V}^{5+}$, or by a superoxo, $\mathrm{O}_{2}{ }^{-}$ion, which leaves one electron in vanadium d-states, resulting in one $\mathrm{V}^{4+}$ and two $\mathrm{V}^{5+}$ ions (Fig. 4). The spins of the $\mathrm{V}^{4+}$ and $\mathrm{O}_{2}{ }^{-}$electrons form either a triplet state or an open shell singlet state. The same or additional superoxo structures can be generated by

Table 3 Relative stability of $\mathrm{V}_{3} \mathrm{O}_{6}{ }^{+}$isomers $E(\mathrm{~kJ} / \mathrm{mol})$, predicted by different methods

\begin{tabular}{llll}
\hline Isomer & Cage & Chain & Ring-2 \\
\hline State & ${ }^{3} A$ & $C_{2}{ }^{-3} \mathrm{~B}$ & ${ }^{3} A$ \\
ROHF-UCCSD(T) $^{a}$ & 0.0 & 7.1 & 17.0 \\
ROHF-UCCSD $^{a}$ & 0.0 & 12.2 & 20.4 \\
ROHF-MP2 $^{a}$ & 0.0 & 8.1 & 37.2 \\
B3LYP/TZVP-df & 0.0 & -11.5 & 0.0 \\
B3LYP/TZVP & $0.0^{b}$ & -9.8 & -2.1 \\
B3LYP/TZVP-df+D & 0.0 & -4.1 & -10.0 \\
B3LYP/TZVP+D & 0.0 & 0.0 & -12.2
\end{tabular}

${ }^{a}$ At the B3LYP/TZVP-df $+\mathrm{D}$ equilibrium structures. Restricted open shell Hartree-Fock reference is used. ${ }^{b}$ The binding energy with respect to $\mathrm{V}_{2} \mathrm{O}_{5}+\mathrm{VO}^{+}$is $4.42 \mathrm{eV}$. 
Table 4 Relative stability of $\mathrm{V}_{3} \mathrm{O}_{8}{ }^{+}$isomers ${ }^{a}$ and their Ar complexes $(\mathrm{kJ} / \mathrm{mol})$ predicted by B3LYP/TZVP. $\Delta E$ is the binding energy of Ar atoms to $\mathrm{V}_{3} \mathrm{O}_{8}{ }^{+}, R$ the $\mathrm{Ar}-\mathrm{V}$ distance in pm. Energies in parenthesis are B3LYP $+\mathrm{D}$ results. See ESI for information on energetically higher-lying isomers

\begin{tabular}{|c|c|c|c|c|c|c|c|}
\hline \multirow[b]{2}{*}{ Isomer } & \multicolumn{3}{|l|}{$\underline{\mathrm{V}_{3} \mathrm{O}_{8}{ }^{+}}$} & \multicolumn{4}{|c|}{$\underline{\mathrm{V}_{3} \mathrm{O}_{8}{ }^{+} \cdot \mathrm{Ar}}$} \\
\hline & State $^{b}$ & $R_{\mathrm{O}-\mathrm{O}}$ & $E$ & State $^{b}$ & $E$ & $R$ & $\Delta E$ \\
\hline$\eta^{2}$-peroxo cage & $C_{\mathrm{s}^{-}}{ }^{1} A^{\prime}$ & 140 & $0^{a}(0)$ & $C_{\mathrm{s}^{-}}{ }^{1} A^{\prime}$ & $12.9(21.0)$ & 296 & $\begin{array}{l}9.6(18.6) \\
13.3(20.8)\end{array}$ \\
\hline$\eta^{2}$-superoxo cage-a & $C_{1^{-}}{ }^{\mathrm{bs}} A$ & 133 & $-4.5(-3.7)$ & & $\begin{array}{l}7.1(18 . /) \\
7.5(16.8) \\
7.5\end{array}$ & $\begin{array}{l}285 \\
295\end{array}$ & $\begin{array}{l}1 . .4(19.1) \\
10.5\end{array}$ \\
\hline $\begin{array}{l}\eta^{2} \text {-superoxo chain-a } \\
\eta^{2} \text {-superoxo chain-b }\end{array}$ & $\begin{array}{l}C_{1^{-}}{ }^{3} A \\
C_{1}-^{3} A\end{array}$ & $\begin{array}{l}130 \\
130\end{array}$ & $\begin{array}{l}6.1 \\
8.6\end{array}$ & & & & \\
\hline$\eta^{2}$-superoxo cage-b & $C_{1}{ }^{3} A$ & 130 & $\begin{array}{l}0.0 \\
11.6\end{array}$ & & 10.8 & 267 & 23.2 \\
\hline $\begin{array}{l}\eta^{2} \text {-superoxo ring } \\
\eta^{2} \text {-superoxo ring }\end{array}$ & $C_{2 \mathrm{v}^{-}}{ }^{3} A_{2}$ & 130 & 13.5 & $\begin{array}{l}{ }^{3} A^{\prime \prime} \\
\mathrm{bs} A^{\prime}\end{array}$ & $\begin{array}{l}31.2 \\
18.0\end{array}$ & $\begin{array}{l}320 \\
264\end{array}$ & $\begin{array}{l}4.7 \\
17.9\end{array}$ \\
\hline $\begin{array}{l}\eta \text {-superoxo ring } \\
\eta^{2} \text {-peroxo ring }\end{array}$ & $C_{2 \mathrm{v}^{-}}{ }^{1} A_{2}$ & 142 & $16.1(8.8)$ & & $\begin{array}{l}18.0 \\
17.3(17.6)\end{array}$ & $\begin{array}{l}204 \\
267\end{array}$ & $21.3(30.8)$ \\
\hline$\eta^{2}$-superoxo ring- 2 & $C_{1^{-}}{ }^{3} A$ & 130 & 19.3 & & 18.0 & 270 & 23.8 \\
\hline$\eta^{2}$-superoxo cage-a & $C_{1^{-}}{ }^{3} A$ & 131 & 25.9 & & & & \\
\hline$\eta^{2}$-superoxo cage & $C_{\mathrm{s}^{-}}{ }^{3} A^{\prime}$ & 130 & 27.5 & & & & \\
\hline$\mu-\left(\eta^{1}-\eta^{1}\right)$-peroxo ring-a & $C_{\mathrm{s}^{-}}{ }^{1} A^{\prime}$ & 141 & $27.6(15.1)$ & & $0(0)$ & 253 & $50.1(54.7)$ \\
\hline$\mu-\left(\eta^{1}-\eta^{1}\right)$-peroxo ring-b & $C_{\mathrm{s}^{-}}{ }^{1} A^{\prime}$ & 141 & $36.3(24.0)$ & & 8.3 & 253 & 50.4 \\
\hline$\mu-\left(\eta^{1}-\eta^{2}\right)$-peroxo cage & $C_{1^{-}}{ }^{-1} A$ & 142 & 31.1 & & 34.5 & 273 & 19.0 \\
\hline$\eta^{2}$-superoxo cage-TS & $C_{\mathrm{s}^{-}}{ }^{3} A^{\prime \prime}$ & 130 & 41.2 & & 36.8 & 276 & 16.7 \\
\hline
\end{tabular}

adding an $\mathrm{O}_{2}$ species to $\mathrm{V}_{3} \mathrm{O}_{6}{ }^{+}$. One of the two $\mathrm{V}^{4+}\left(\mathrm{d}^{1}\right)$ sites in $\mathrm{V}_{3} \mathrm{O}_{6}{ }^{+}$donates its electron to $\mathrm{O}_{2}$, creating a superoxo species with one electron in its antibonding $\pi$-orbitals. This results in the multitude of low energy singlet peroxo structures and triplet/open shell singlet superoxo structures listed in Table 4 which also provides $\mathrm{O}-\mathrm{O}$ distances. Fig. 4 shows some of these structures (see ESI§ for additional structures).

Most stable are a (closed shell) singlet $\eta^{2}$-peroxo cage structure $\left(C_{\mathrm{s}^{-}}{ }^{1} A^{\prime}\right.$, Fig. 4) and the open shell singlet state of the superoxo cage-a structure (Fig. 5) with one unpaired electron in the $\mathrm{O}_{2}$ unit and the other in a d-orbital of the $\mathrm{V}$ atom to which the $\mathrm{O}_{2}$ unit is attached. With single determinants as used in Kohn-Sham-DFT, open shell singlets can only be described by broken-symmetry solutions, which indicates a $4.5 \mathrm{~kJ} / \mathrm{mol}$ lower energy for the superoxo structure compared to the peroxo structure. The broken-symmetry solution is a mixture of pure triplet and singlet states, and since overlap between the singly occupied orbitals at the $\mathrm{V}\left(\mathrm{d}^{1}\right)^{4+}$ center and the $\mathrm{O}_{2}{ }^{-}$superoxo moiety is not negligible, it provides only an approximate energy for the low spin state.

Hence, the relative energy of the $\eta^{2}$-peroxo or $\eta^{2}$-superoxo cage structures remains questionable. Additional calculations by wavefunction based electron correlation methods have been

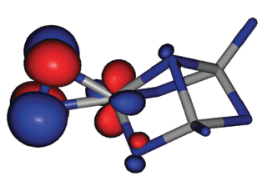

cage-a

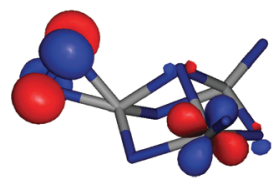

cage-b
Fig. 5 Different localisation of the singly occupied natural orbitals (NOs) in the $\eta^{2}$-superoxo cage-a (left) and cage-b (right) structures of $\mathrm{V}_{3} \mathrm{O}_{8}{ }^{+}$. Both show contributions from the antibonding $\pi$ orbital of the superoxo species, but differ in the localization of the d-orbital, which is either at the $\mathrm{V}$ site to which the superoxo species is attached (cage-a) or further apart at one of the $\mathrm{V}$ sites bearing a vanadyl group (cage-b). performed at the geometric structures predicted by B3LYP/ TZVP. Both CCSD(T) and CAS(8,8)-PT2 (with 8 p electrons of $\mathrm{O}_{2}{ }^{-}$in the active space) confirm the multi-reference character of the problem, but do not yield a definitive answer. Whereas $\operatorname{CCSD}(\mathrm{T}) / \mathrm{TZVP}$ predicts the superoxo structure $12.1 \mathrm{~kJ} / \mathrm{mol}$ more stable ( $\mathrm{T} 1 \mathrm{diagnostics}$ high, peroxo: 0.06, superoxo: 0.08), CAS-PT2 yields the peroxo structure $7.7 \mathrm{~kJ} / \mathrm{mol} \mathrm{more} \mathrm{stable.}$

The triplet $\eta^{2}$-superoxo cage-a $\left(C_{1}\right)$ and $\eta^{2}$-superoxo $\left(C_{\mathrm{s}}\right)$ cage structures of the same type (unpaired electron in the $\mathrm{O}_{2}$ unit and in a d-state of the adjacent $\mathrm{V}$ atom) are 25.9 and $27.5 \mathrm{~kJ} / \mathrm{mol}$, respectively, above the $\eta^{2}$-peroxo cage structure. If one of the two unpaired electrons is not localized on the $\mathrm{V}$ site bearing the $\mathrm{O}_{2}{ }^{-}$unit as shown on the left of Fig. 5, but on one of the neighbouring vanadyl groups, as shown for the $\eta^{2}$ superoxo cage-b $\left(C_{1}\right)$ structure on the right of Fig. 5, the interaction is weaker and a less stable structure results.

There are two vanadyl sites in the cage structure, and we have also been able to localize a $C_{\mathrm{s}^{-}}{ }^{3} A^{\prime \prime}$ structure with equivalent d-orbital contributions on both vanadyl sites (Fig. 6, right). This structure, which has a symmetry plane and is $29.6 \mathrm{~kJ} / \mathrm{mol}$ above the $\eta^{2}$-superoxo cage-b structure (Fig. 6, left), does not represent a local minimum, but is the transition structure for the electron jump between the two sites. With solid oxides this type of electron transport is known as polaron hopping, see, e.g. ref. 43, and the present calculations on $\mathrm{V}_{3} \mathrm{O}_{8}{ }^{+}$provide a simple model estimate of the energy barrier for polaron hopping in vanadium oxides. It is of the same order of magnitude as found before for titanium oxide, ${ }^{43} 29 \mathrm{~kJ} / \mathrm{mol}$ for non-adiabatic and $10 \mathrm{~kJ} / \mathrm{mol}$ for adiabatic hopping.

Two $\eta^{2}$-superoxo structures that result from the most stable $\mathrm{V}_{3} \mathrm{O}_{6}{ }^{+}$chain structure, $\eta^{2}$-superoxo chain-a/b, and feature a $\mathrm{V}^{4+}\left(\mathrm{d}^{1}\right)$ unit at one and $\mathrm{a} \mathrm{V}^{5+}\left(\mathrm{O}_{2}{ }^{-}\right)$unit at the other end (see Fig. 7) are at energies between the cage-a and cage-b structures. The large distance between the unpaired electrons explains the fact that triplet and singlet states are energetically degenerate. 

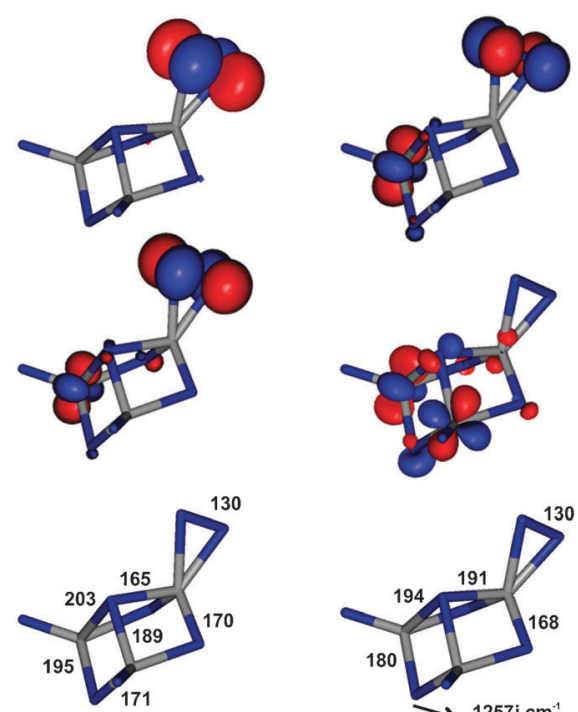

$\eta^{2}$-superoxo-cage- $b$ $\mathrm{C}_{1}{ }^{3} \mathrm{~A}(0.0)$

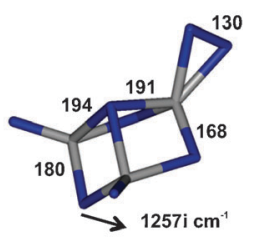

$\eta^{2}$-superoxo-cage-TS $\mathrm{C}_{\mathrm{s}}{ }^{3} \mathrm{~A}^{\prime \prime}(+29.6)$
Fig. 6 The $\eta^{2}$-superoxo cage structure of $\mathrm{V}_{3} \mathrm{O}_{8}{ }^{+}$with an electron localized in a d-state of one of the vanadyl sites (left) compared to the $C_{\mathrm{s}}$ transition structure with two equivalent vanadyl sites (right). Bond lengths are in pm and energies (relative to structure on the left) in $\mathrm{kJ} / \mathrm{mol}$. The vibrational mode with imaginary frequency is indicated. Above the geometric structures the two NOs are shown. Note that the two NOs shown on the left could be transformed into one orbital localized in the $\mathrm{O}_{2}$ unit and another one localized at the $\mathrm{V}$ site.
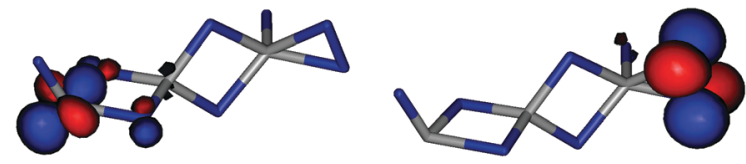

Fig. 7 Localisation of the singly occupied NOs at opposite ends of the $\eta^{2}$-superoxo chain structure of $\mathrm{V}_{3} \mathrm{O}_{8}{ }^{+}$. At one end there is the vanadium $d$ orbital (left) and at the other end the $\pi$ orbital of the superoxo species (right).

There are two energetically close isomers $(3 \mathrm{~kJ} / \mathrm{mol})$ that differ by the orientation of the superoxo group with respect to the $\mathrm{VO}_{2} \mathrm{~V}$ planes.

The most stable ring structure, $\eta^{2}$-superoxo ring $\left(C_{2 \mathrm{v}^{-}}{ }^{3} A_{2}\right)$, is obtained by replacing the terminal $\mathrm{O}^{2-}$ in the $\mathrm{OV}^{(+)}(\mathrm{O}-)_{2}$ unit of the $\mathrm{V}_{3} \mathrm{O}_{7}{ }^{+}$ring structure with $\mathrm{O}_{2}{ }^{-}$, which leaves one electron in $\mathrm{V}$-d states on this site and one unpaired electron in superoxo p-orbitals. Pairing of these electrons yields the corresponding peroxo structure which is only $2 \mathrm{~kJ} / \mathrm{mol}$ less stable. There is another superoxo ring structure (labelled $\eta^{2}$-ring-2 in the ESI§) with three nonequivalent $\mathrm{V}$ sites, two $\mathrm{V}^{5+}$ sites with five-fold and four-fold coordination, and a three-fold coordinated $\mathrm{V}\left(\mathrm{d}^{1}\right)^{4+}$ site.

Rare gas complexes of $\mathrm{V}_{\mathbf{3}} \mathrm{O}_{\mathbf{6}-\mathbf{8}}{ }^{+}$. Fig. 2-4 also show low energy structures of $\mathrm{V}_{3} \mathrm{O}_{7}{ }^{+} \cdot \mathrm{Ar}, \mathrm{V}_{3} \mathrm{O}_{6}{ }^{+} \cdot \mathrm{He}_{1,2,4}$, and $\mathrm{V}_{3} \mathrm{O}_{8}{ }^{+} \cdot \mathrm{Ar}$ complexes, respectively. Binding energies and bond distances are provided in Tables 2 and 4-6. The binding of $\mathrm{Ar}$ is strongest $(\sim 55 \mathrm{~kJ} / \mathrm{mol})$ to threefold coordinated $\mathrm{V}^{(+)}$sites with a formal positive charge, as present in the ring structure of $\mathrm{V}_{3} \mathrm{O}_{7}{ }^{+}$(Table 2) and in the $\mu-\left(\eta^{1}-\eta^{1}\right)$-peroxo ring-a structure
Table 5 Relative stability of $\mathrm{V}_{3} \mathrm{O}_{8}{ }^{+}$isomers and their complexes with one and two Ar atoms, $E(\mathrm{~kJ} / \mathrm{mol})$, predicted by $\mathrm{B} 3 \mathrm{LYP} / \mathrm{TZVP}+\mathrm{D}$. $\Delta E(\mathrm{~kJ} / \mathrm{mol})$ is the binding energy of Ar atoms on $\mathrm{V}_{3} \mathrm{O}_{8}{ }^{+}$, and $R$ the $\mathrm{Ar}-\mathrm{V}$ distance (pm). B3LYP results without dispersion are given in parenthesis

\begin{tabular}{llll}
\hline Isomer & $\eta^{2}$-peroxo cage & $\eta^{2}$-peroxo ring & TS cage-ring \\
\hline $\mathrm{V}_{3} \mathrm{O}_{8}{ }^{+}$ & $C_{\mathrm{s}^{-}}{ }^{1} A^{\prime}$ & $C_{2 \mathrm{v}^{-}}{ }^{1} A_{1}$ & $C_{\mathrm{s}^{-}}{ }^{1} A^{\prime}$ \\
$E$ & $0.0(0.0)$ & $8.8(16.1)$ & $17.1(22.2)$ \\
$\mathrm{V}_{3} \mathrm{O}_{8}{ }^{+} \cdot \mathrm{Ar}$ & $C_{1}{ }^{-}{ }^{1} A$ & $C_{\mathrm{s}^{-}}{ }^{-} A^{\prime}$ & $C_{\mathrm{s}}{ }^{1} A^{\prime}$ \\
$R$ & 283 & 266 & 277 \\
$\Delta E$ & $20.8(13.3)$ & $30.8(21.3)$ & $25.7(18.4)$ \\
$E$ & $0.0(0.0)$ & $-1.1(8.2)$ & $12.3(17.2)$ \\
$\mathrm{V}_{3} \mathrm{O}_{8}{ }^{+} \cdot \mathrm{Ar}_{2}$ & $C_{\mathrm{s}^{-}}{ }^{1} A^{\prime}$ & $C_{1}{ }^{1} A$ & $C_{1}{ }^{1} A$ \\
$\mathrm{R} / \mathrm{R}$ & $288 / 288$ & $268 / 333$ & $277 / 316$ \\
$\Delta E$ & $40.0(24.7)$ & $42.2(23.2)$ & $39.5(22.4)$ \\
$E$ & $0.0(0.0)$ & $6.6(17.6)$ & $17.6(24.5)$ \\
\hline
\end{tabular}

of $\mathrm{V}_{3} \mathrm{O}_{8}{ }^{+}$(Table 4). Next come fourfold coordinated $\mathrm{V}^{(+)}$ sites with a formal positive charge, as in the $\mu-\left(\eta^{2}-\eta^{2}\right)$-peroxo and $\eta^{2}$-peroxo ring structures of $\mathrm{V}_{3} \mathrm{O}_{8}{ }^{+}$(49 and $31 \mathrm{~kJ} / \mathrm{mol}$, respectively, ESI§).

The binding of Ar to $\mathrm{V}_{3} \mathrm{O}_{7}{ }^{+}$is much weaker for the cage structure (4-fold coordinated $\mathrm{V}$ with delocalized formal charge) than for the ring structure (Table 2). This leads to a reversal of the relative stability of the two isomers: without $\mathrm{Ar}$ the cage is most stable, while in the presence of Ar, the ring structure is more stable. The cage structure may disappear completely as a minimum on the potential energy surface if the binding is even stronger, which has indeed been found for the $\mathrm{V}_{3} \mathrm{O}_{7}{ }^{+}$-propane complex. ${ }^{21}$

Also for $\mathrm{V}_{3} \mathrm{O}_{8}{ }^{+}$the binding of Ar to the $\mathrm{O}=\mathrm{V}(\mathrm{O}-)_{3}$ site of the cage structure $(21 \mathrm{~kJ} / \mathrm{mol})$ is much weaker than to the fourfold coordinated $\mathrm{V}^{(+)}$site of the ring structure $(31 \mathrm{~kJ} / \mathrm{mol}$, Table 5). This leads to a reversal of the relative stability of the two isomers, in the presence of Ar, the ring structure becomes slightly more stable. However, the cage structure has two equivalent $\mathrm{O}=\mathrm{V}(\mathrm{O}-)_{3}$ sites to which two Ar atoms can bind with about the same strength $(20 \mathrm{~kJ} / \mathrm{mol})$, whereas the binding of the second Ar atom to the ring structure is much weaker $(11 \mathrm{~kJ} / \mathrm{mol}$, Table 5). This again reverses the stability sequence and for $\mathrm{V}_{3} \mathrm{O}_{8}{ }^{+} \cdot \mathrm{Ar}_{2}$ the cage structure is $7 \mathrm{~kJ} / \mathrm{mol}$ more stable than the ring structure.

The He binding energies are lower, about $10-12 \mathrm{~kJ} / \mathrm{mol}$ per $\mathrm{He}$ atom (including dispersion). The chain and cage structures of $\mathrm{V}_{3} \mathrm{O}_{6}{ }^{+}$bind one and two $\mathrm{He}$ atoms with about the same strength (10 to $12 \mathrm{~kJ} / \mathrm{mol}$ per $\mathrm{He}$ atom, Table 6 ). However, in contrast to the cage structure, which has only two binding sites of this strength, the chain structure has four almost equivalent binding sites. Specifically, the $\mathrm{He}$ binding energies (per He atom) show the following sequence: cage-He (11.8) > chain-He (11.3) > (chain-He)-He (11.0) > $($ chain-He-He)He-He $(10.3)>($ cage-He)-He-anti (9.6). This indicates that in a mixture of chain and cage isomers, formation of chain- $\mathrm{He}_{4}$ complexes will be energetically favourable compared to formation of a cage- $\mathrm{He}_{2}$ complex.

\subsection{Assignment of the vibrational spectra}

To identify the absorbing species and assign the vibrational spectra, we calculated scaled harmonic vibrational frequencies and intensities of all the structural candidates. The stick spectra 
Table 6 Relative stability $E$ of $\mathrm{V}_{3} \mathrm{O}_{6}{ }^{+}$isomers and their He complexes, predicted by B $3 L Y P / T Z V P+D . \Delta E$ and $\Delta E_{\text {zpe }}$ are the binding energies of all $\mathrm{He}$ atoms to $\mathrm{V}_{3} \mathrm{O}_{6}{ }^{+}$without and with zero point energy, respectively, and $R$ is the $\mathrm{He}-\mathrm{V}$ distance in pm. All energies are in $\mathrm{kJ} / \mathrm{mol}$. $\mathrm{B} 3 \mathrm{LYP}$ results without dispersion are given in parenthesis

\begin{tabular}{|c|c|c|c|c|c|c|}
\hline & \multicolumn{6}{|l|}{$\mathrm{V}_{3} \mathrm{O}_{6}{ }^{+} \cdot \mathrm{He}_{n}$} \\
\hline & Isomer & $R$ & $\Delta E$ & Diff $^{a}$ & $\Delta E_{\text {zpe }}$ & $E_{\text {rel }}(\mathrm{CC})-\Delta E^{c}$ \\
\hline \multirow[t]{3}{*}{ Cage } & $\mathrm{He}$ & 216 & $11.8(10.3)$ & \multirow{3}{*}{$9.6(7.3)$} & 9.0 & -11.8 \\
\hline & $\mathrm{He}-\mathrm{He}$-anti & $215 / 216$ & $21.4(17.6)$ & & 15.3 & -21.4 \\
\hline & $\mathrm{He}_{2}$ & $216 / 241$ & $19.1(15.6)$ & & 14.4 & -19.1 \\
\hline \multirow[t]{4}{*}{ Chain } & $\mathrm{He}\left({ }^{3} B\right)$ & 213 & $11.3(9.7)$ & \multirow{5}{*}{$\begin{array}{l}11.0(9.3) \\
10.3(8.6)^{b}\end{array}$} & 8.0 & -4.2 \\
\hline & $\mathrm{He}_{2}\left({ }^{3} A\right)$ & $214 / 215$ & $21.8(18.3)$ & & 15.3 & -14.7 \\
\hline & $\mathrm{He}-\mathrm{He}\left(C_{2^{-}}{ }^{3} B\right)$ & 213 & $22.3(19.0)$ & & 15.8 & -15.2 \\
\hline & $\mathrm{He}_{2}-\mathrm{He}_{2}\left(C_{2}{ }^{3} B\right)$ & 215 & $42.5(35.5)$ & & 29.8 & -35.4 \\
\hline \multirow[t]{3}{*}{ Ring-2 } & $\mathrm{He}$ & 216 & $9.6(7.8)$ & & & 7.4 \\
\hline & $\mathrm{He}-\mathrm{He}$-anti & $216 / 247$ & $15.9(12.2)$ & \multirow[t]{2}{*}{$6.3(4.4)$} & & 1.1 \\
\hline & $\mathrm{He}_{2}-\mathrm{He}$ & $218 / 249 / 257$ & $21.1(-)$ & & & -4.1 \\
\hline
\end{tabular}

${ }^{a}$ Difference to binding energy of the respective $\mathrm{He}_{1}$ complex. ${ }^{b}$ Per He atom with respect to the He-He $\left({ }^{3} B\right) \operatorname{complex} .{ }^{c}$ Relative CCSD(T) energy (Table 3) minus He binding energy, $\Delta E$.

obtained were finally convoluted with a Gaussian line function, with FWHM-widths of $10 \mathrm{~cm}^{-1}$, for better comparability.

$\mathbf{V}_{\mathbf{3}} \mathbf{O}_{\mathbf{7}}{ }^{+} \cdot \mathbf{A r}_{\mathbf{0 , 1}}$. The simulated linear absorption spectra of the highly symmetric cage isomer $\left(C_{3 \mathrm{v}}\right)$, the global ground state for $\mathrm{V}_{3} \mathrm{O}_{7}{ }^{+}$, shows excellent agreement with the measured IRPD spectrum of bare $\mathrm{V}_{3} \mathrm{O}_{7}{ }^{+}$regarding the number of peaks and their positions (see top two spectra in Fig. 8). In particular, the simulated spectrum accounts for all the five observed features $\left(b_{1}-b_{5}\right)$. Bands $b_{1}$ and $b_{2}$ are assigned to three vanadyl stretching modes, one mode of $a_{1}$ symmetry $\left(1066 \mathrm{~cm}^{-1}\right)$ and

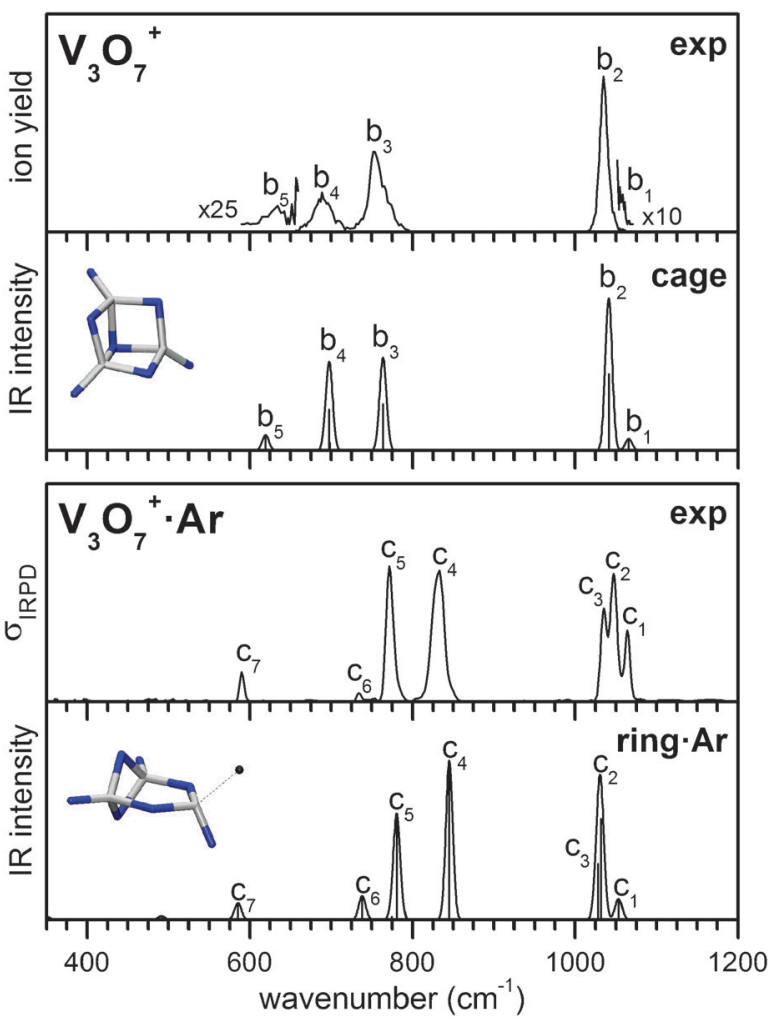

Fig. 8 Experimental IRPD spectra of $\mathrm{V}_{3} \mathrm{O}_{7}{ }^{+}$and $\mathrm{V}_{3} \mathrm{O}_{7}{ }^{+} \cdot \mathrm{Ar}$ (same as in Fig. 1) and simulated linear absorption spectra in the range from 350 to $1200 \mathrm{~cm}^{-1}$ of the cage and ring Ar isomers. Peak positions of features labelled with indexed letters are listed in Table 1. two degenerate modes of $e$ symmetry $\left(1041 \mathrm{~cm}^{-1}\right)$. Bands $\mathrm{b}_{3}$, $\mathrm{b}_{4}$ and $\mathrm{b}_{5}$ are assigned to six $\mathrm{V}-\mathrm{O}-\mathrm{V}$ stretching modes at $764(e)$, $698\left(a_{1}\right), 697(e)$ and $619 \mathrm{~cm}^{-1}\left(a_{1}\right)$.

The experimental IRPD spectrum of $\mathrm{V}_{3} \mathrm{O}_{7}{ }^{+} \cdot \mathrm{Ar}$ in Fig. 8 cannot be assigned to the simulated spectrum of the cage structure. However, a satisfactory agreement is found upon comparison to that of the ring isomer. Moreover, absorption of exclusively this species is sufficient to explain all the experimentally observed peaks. The assignment of the peaks to vibrational modes is similar to the previous spectrum. Bands $c_{1}$ to $c_{3}$ and $c_{4}$ to $c_{7}$ are assigned to the three vanadyl and six $\mathrm{V}-\mathrm{O}-\mathrm{V}$ stretching modes, respectively. The calculated energies predicted a reversal of the energetic ordering of the cage and the ring isomer (see above), due to substantially different cation-Ar binding energies (see Table 2), substantiating our assignment.

$\mathbf{V}_{\mathbf{3}} \mathbf{O}_{\mathbf{8}}{ }^{+} \cdot \mathbf{A r}_{\mathbf{0}, \mathbf{2}}$. The predicted IR spectra for the $\eta^{2}$-superoxo chain (triplet) and the $\eta^{2}$-superoxo ring species (singlet) of $\mathrm{V}_{3} \mathrm{O}_{8}{ }^{+}$, which are only +6.1 and $+13.5 \mathrm{~kJ} / \mathrm{mol}$, respectively, above the $\eta^{2}$-peroxo cage structure, do not match the experimental spectrum (see Fig. 9) and can thus be excluded from the assignment. The spectra of the $\eta^{2}$-superoxo and $\eta^{2}$-peroxo cage isomers (singlets) are rather similar, the main difference being the position and relative intensity of the band at $1095 \mathrm{~cm}^{-1}$ (superoxo) and $992 \mathrm{~cm}^{-1}$ (peroxo), respectively. Smaller differences are observed for the spacing of the vanadyl bands (12 vs. $\left.18 \mathrm{~cm}^{-1}\right)$ as well as the position of the $\mathrm{V}-\mathrm{O}-\mathrm{V}$ stretching bands below $800 \mathrm{~cm}^{-1}$. Whereas a slightly better agreement is found for the superoxo cage structure in the region below $800 \mathrm{~cm}^{-1}$, observation of the band at $994 \mathrm{~cm}^{-1}$ $\left(d_{2}\right)$ strongly favours the assignment to the peroxo cage structure. The $\eta^{2}$-peroxo cage, and not the $\eta^{2}$-superoxo cage structure, is clearly observed when two Ar atoms are present. All eight bands $\mathrm{e}_{1}$ to $\mathrm{e}_{8}$ of the $\mathrm{V}_{3} \mathrm{O}_{8}{ }^{+} \cdot \mathrm{Ar}_{2}$ spectrum (Fig. 10) are reproduced by the simulated spectrum of this isomer.

$\mathbf{V}_{3} \mathbf{O}_{6}{ }^{+} \cdot \mathbf{H e}_{1-4}$. The simulated IR spectra of the three lowest energy isomers of $\mathrm{V}_{3} \mathrm{O}_{6}{ }^{+}$, chain, cage and ring-2, calculated within $10 \mathrm{~kJ} / \mathrm{mol}$ of each other, are all characteristically different (Fig. 11) and only the chain and the cage isomer are compatible with the experimental IRPD spectra of $\mathrm{V}_{3} \mathrm{O}_{6}{ }^{+} \cdot \mathrm{He}$ (see Fig. 1). 


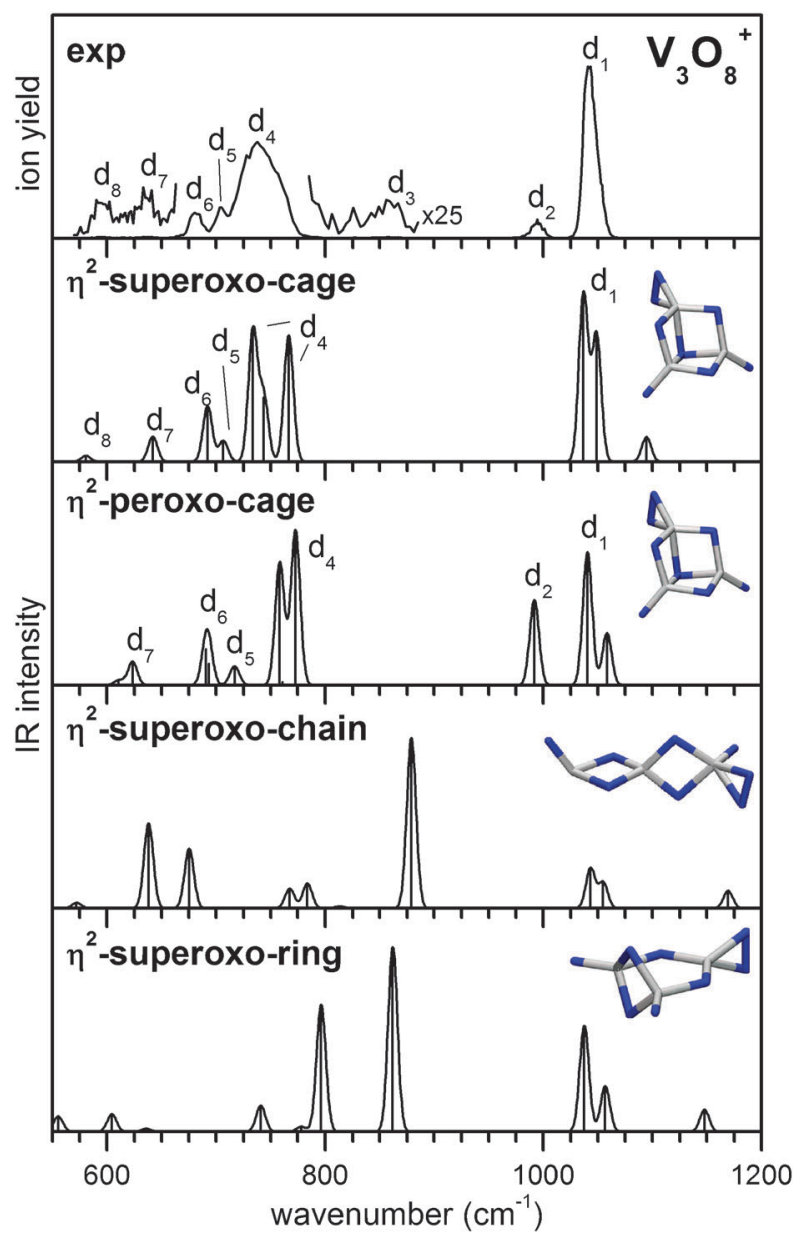

Fig. 9 Experimental IRPD spectrum of $\mathrm{V}_{3} \mathrm{O}_{8}{ }^{+}$(the same as in Fig. 1) and simulated linear absorption spectra of the $\eta^{2}$-superoxo cage, $\eta^{2}$-peroxo cage, $\eta^{2}$-superoxo chain and $\eta^{2}$-superoxo ring isomers in the range from 550 to $1200 \mathrm{~cm}^{-1}$. Peak positions of features labelled with indexed letters are listed in Table 1.

The IR signatures of the individual isomers can be isolated due to a fortuitous difference in the ion-He atom sequential binding energies, resulting in only one of these two isomers

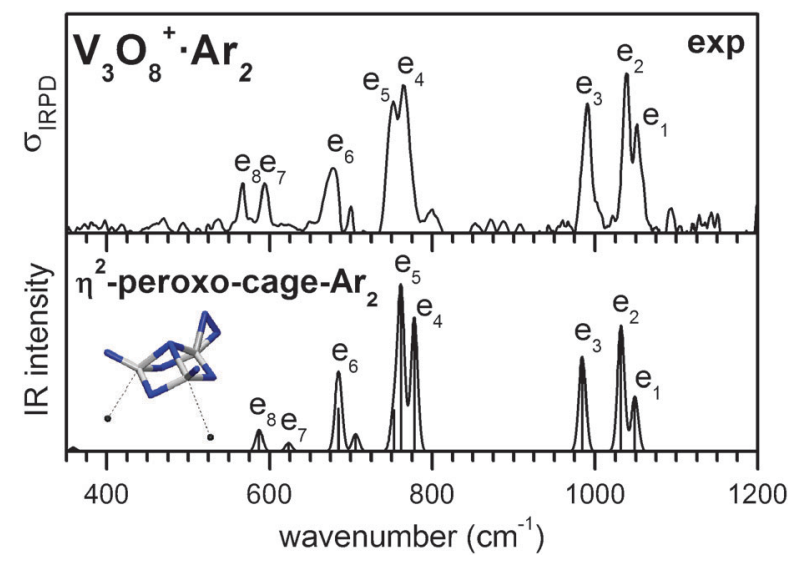

Fig. 10 Experimental IRPD spectrum of $\mathrm{V}_{3} \mathrm{O}_{8}{ }^{+} \cdot \mathrm{Ar}_{2}$ (the same as in Fig. 1) compared to simulated linear absorption spectra of the $\eta^{2}$-peroxo cage $\mathrm{Ar}_{2}$ structure in the range from 350 to $1200 \mathrm{~cm}^{-1}$. Peak positions of features labelled with indexed letters are listed in Table 1.

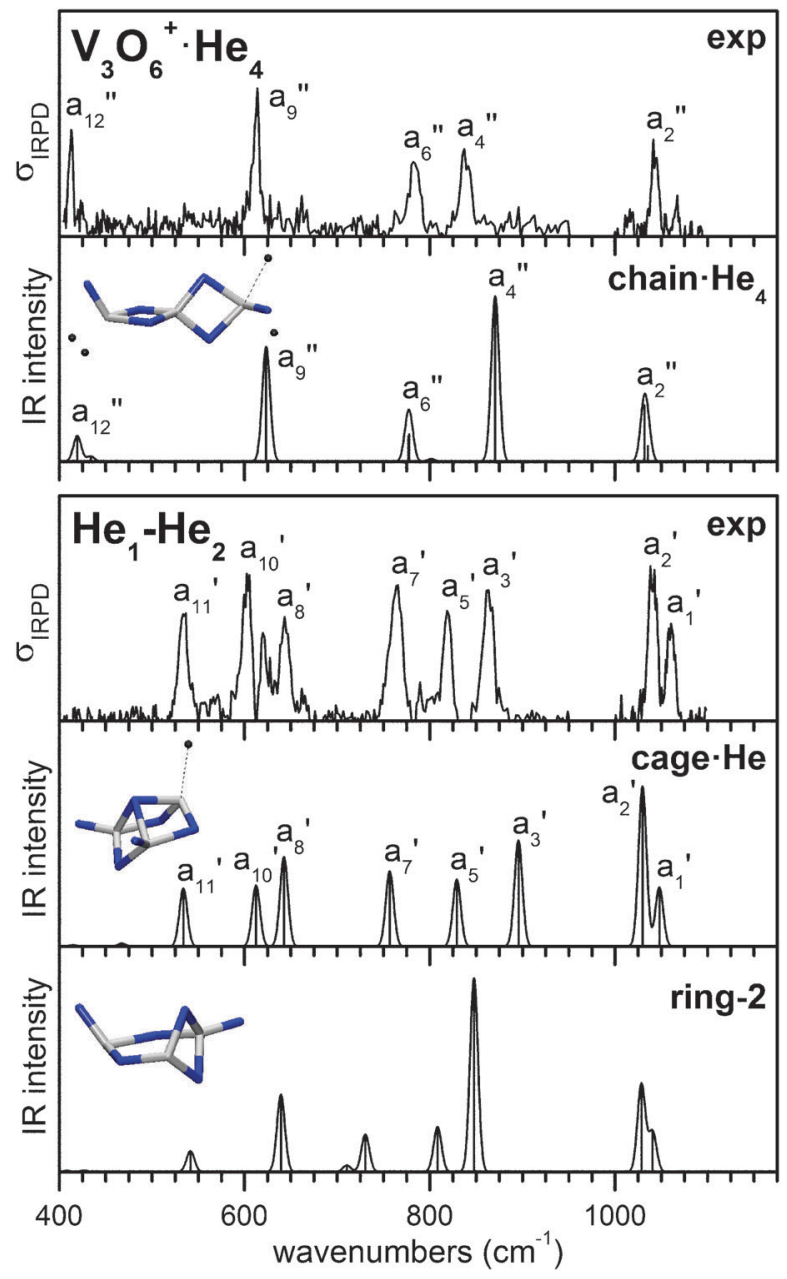

Fig. 11 Experimental IRPD spectra of $\mathrm{V}_{3} \mathrm{O}_{6}{ }^{+} \cdot \mathrm{He}_{n}$ (see text) compared to simulated linear absorption spectra of the chain. $\mathrm{He}_{4}$, cage $\cdot \mathrm{He}$ and ring- 2 isomers in the range from 400 to $1175 \mathrm{~cm}^{-1}$. Peak positions of features labelled with indexed letters are listed in Table 1.

binding more than a single $\mathrm{He}$ atom efficiently. As a consequence, the IR spectrum of $\mathrm{V}_{3} \mathrm{O}_{6}{ }^{+} \cdot \mathrm{He}_{4}$ (top spectrum in Fig. 11) is considerably simpler than the $\mathrm{V}_{3} \mathrm{O}_{6}{ }^{+} \cdot \mathrm{He}$ spectrum and peaks $a_{2}^{\prime \prime}, a_{4}^{\prime \prime}, a_{6}^{\prime \prime}, a_{9}^{\prime \prime}$ and $a_{12}^{\prime \prime}$ can unambiguously be assigned to the chain isomer. Subtraction of the $\mathrm{V}_{3} \mathrm{O}_{6}{ }^{+} \cdot \mathrm{He}_{2}$ spectrum from the $\mathrm{V}_{3} \mathrm{O}_{6}{ }^{+} \cdot \mathrm{He}$ spectrum (see ESI§) then yields the IR fingerprint of the second absorbing species $\left(\mathrm{He}_{1}-\mathrm{He}_{2}\right.$ spectrum in Fig. 11). This spectrum matches that calculated for the cage very well.

This characteristic difference in ion-He atom sequential binding energies is also predicted by theory. The cage isomer binds a single He-atom the strongest $(11.8 \mathrm{~kJ} / \mathrm{mol})$. However, the sequential binding energy for the addition of a second $\mathrm{He}$ atom to the cage isomer $(9.6 \mathrm{~kJ} / \mathrm{mol})$ is less than the calculated energies for the addition of the first, the second, the third or the fourth He-atom to the chain isomer (11.3, 11.0, and $10.0 \mathrm{~kJ} / \mathrm{mol}$ per $\mathrm{He}$ atom, respectively, Table 6). The ringisomer binds a single $\mathrm{He}$ atom with $9.6 \mathrm{~kJ} / \mathrm{mol}$ only, and the second and the third He atom with only 6.3 and $5.2 \mathrm{~kJ} / \mathrm{mol}$, respectively, Table 6 . Consequently, at a suitable partial pressure of $\mathrm{He}$, cage- $\mathrm{He}_{1}$ complexes will coexist with chain- $\mathrm{He}_{1-4}$ complexes, whereas $\mathrm{He}$ complexes of rings will not form. 


\section{Discussion}

The assignment of the IRPD spectra of $\mathrm{V}_{3} \mathrm{O}_{7}{ }^{+}$. $\mathrm{Ar}$ and $\mathrm{V}_{3} \mathrm{O}_{8}{ }^{+}$. $\mathrm{Ar}_{2}$ to the ring and cage isomers, respectively, becomes understandable recalling how the Ar complexes are actually formed. They are not produced in the supersonic expansion in the source region, but rather inside the ion trap, starting out from mass-selected, bare cations. The IRPD spectra show that the bare cations of both $\mathrm{V}_{3} \mathrm{O}_{7}{ }^{+}$and $\mathrm{V}_{3} \mathrm{O}_{8}{ }^{+}$have cage-like structures. In the case of $\mathrm{V}_{3} \mathrm{O}_{7}{ }^{+}$the cage isomer is then, through collisions with the buffer gas atoms, efficiently interconverted into the ring isomer of the $\mathrm{V}_{3} \mathrm{O}_{7}{ }^{+} \cdot \mathrm{Ar}$ complex, whereas the $\mathrm{V}_{3} \mathrm{O}_{8}{ }^{+} \cdot \mathrm{Ar}_{2}$ complex retains its cage like structure. This suggests that the isomerization of $\mathrm{V}_{3} \mathrm{O}_{7}{ }^{+}$induced by $\mathrm{Ar}$ complex formation should proceed without a barrier or that the barrier should be small, i.e. comparable to the thermal energy of the buffer gas, which is held at $50 \mathrm{~K}$. Indeed, $\mathrm{B} 3 \mathrm{LYP}+\mathrm{D}$ calculations for $\mathrm{V}_{3} \mathrm{O}_{7}{ }^{+}$(Table 2 and Fig. 12) show that upon addition of $\mathrm{Ar}$ to the cage species, $\mathrm{Ar}$ complexes of both the cage structure and the ring structure can be formed without a barrier. The energy of the cage-ring transition structure for the $\mathrm{Ar}$ complex is $8 \mathrm{~kJ} / \mathrm{mol}$ below the energy of the cage structure plus the Ar atom at large distance (Table 2 and Fig. 12). The reason is that Ar binds most strongly to the ring structure $(55 \mathrm{~kJ} / \mathrm{mol})$ and less strongly to the cage-ring transition structure as well as the cage structure (34 and $23 \mathrm{~kJ} / \mathrm{mol}$, respectively).

Table 2 and Fig. 12 also show results for the Ne complex of $\mathrm{V}_{3} \mathrm{O}_{7}{ }^{+}$. The ring structure binds the $\mathrm{Ne}$ atom twice as strongly as the cage structure (21 compared to $10 \mathrm{~kJ} / \mathrm{mol}$ ), which also makes the ring isomer more stable than the cage isomer, although only marginally, by $3 \mathrm{~kJ} / \mathrm{mol}$. However, the transition structure binds the $\mathrm{Ne}$ atom only weakly, and remains $22 \mathrm{~kJ} / \mathrm{mol}$ above

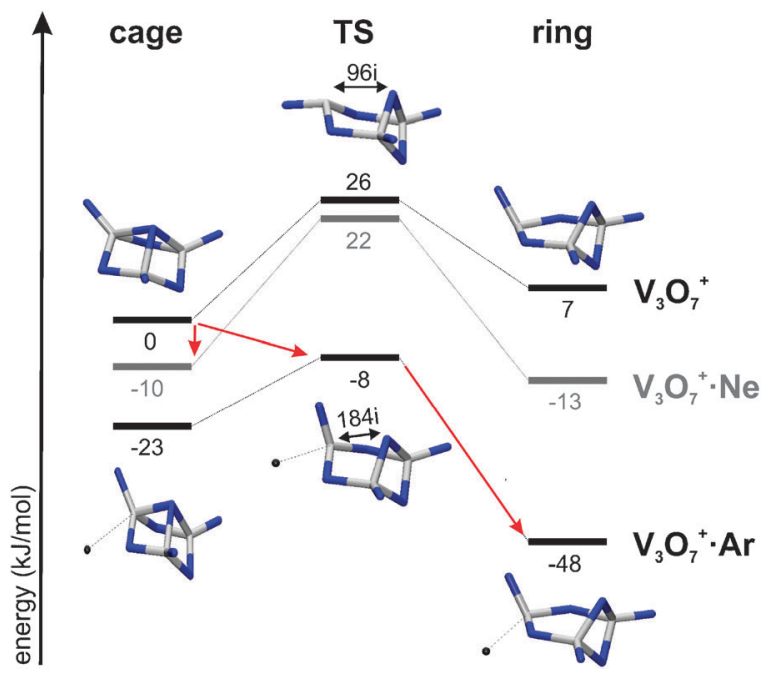

Fig. 12 Schematic energy level diagram $(B 3 L Y P+D)$ of the cage (left) and ring (right) isomers of $\mathrm{V}_{3} \mathrm{O}_{7}{ }^{+}$as well as the transition structure TS (center) connecting the two isomers of the bare ions (top), the corresponding Ne- (center) and Ar-complexes (bottom). Structures, isomerization coordinate and imaginary frequency $\left(\mathrm{cm}^{-1}\right)$ of the transition mode are indicated for the bare ions, as well as for the Arcomplexes. Red arrows indicate formation paths of experimentally observed complexes.

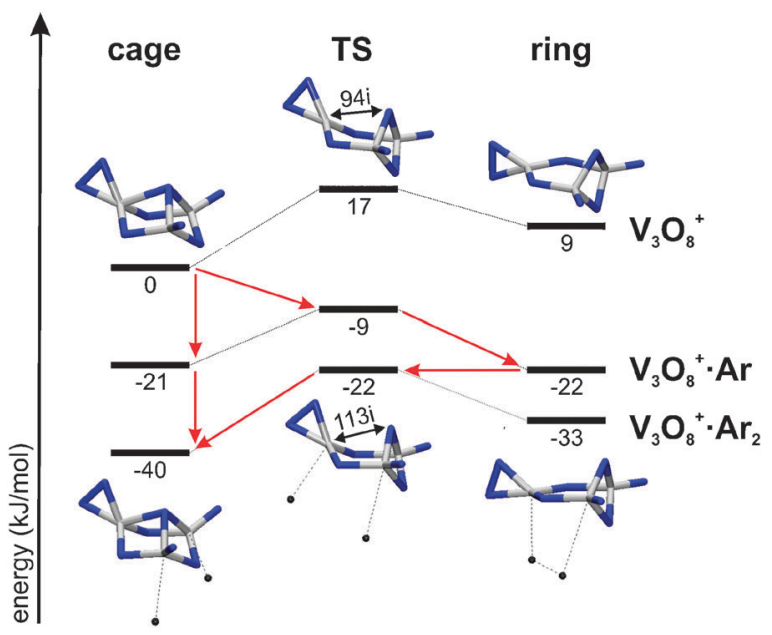

Fig. 13 Schematic energy level diagram $(B 3 L Y P+D)$ of the $\eta^{2}$ peroxo cage (left) and ring (right) isomers of $\mathrm{V}_{3} \mathrm{O}_{8}{ }^{+}$as well as the transition structure TS (center) connecting the two isomers of the bare ions (top), the corresponding Ar- (center) and $\mathrm{Ar}_{2}$-complexes (bottom). Structures, isomerization coordinate and imaginary frequency $\left(\mathrm{cm}^{-1}\right)$ of the transition mode are indicated for the bare ions, as well as for the $\mathrm{Ar}_{2}$-complexes. Red arrows indicate formation paths of experimentally observed complexes.

the energy of the cage structure plus the Ne atom at large distance, which prevents crossing the isomerization barrier. Indeed, the IRPD spectrum of $\mathrm{V}_{3} \mathrm{O}_{7}{ }^{+} \cdot \mathrm{Ne}$ (see ESI§) gives no indication of the ring isomer.

The same $S_{N}$ 2-like reaction can also convert the $\eta^{2}$ - peroxo cage into the $\eta^{2}$-peroxo ring species of $\mathrm{V}_{3} \mathrm{O}_{8}{ }^{+}$(Fig. 13). Adding $\mathrm{Ar}$ as an additional ligand to the vanadium site, vanadium gives up its bond to the threefold coordinated $\mathrm{O}$ atom of the cage structure in an almost linear Ar...V-O arrangement. Also in this case, the Ar binding energy (Table 5) is largest for the ring $(31 \mathrm{~kJ} / \mathrm{mol})$, smaller for the transition structure $(26 \mathrm{~kJ} / \mathrm{mol})$ and smallest for the cage structure (21 kJ/mol). Similarly to $\mathrm{V}_{3} \mathrm{O}_{7}{ }^{+}$, on addition of Ar to the $\eta^{2}$-peroxo $\mathrm{V}_{3} \mathrm{O}_{8}{ }^{+}$cage structure, $\mathrm{Ar}$ complexes of both the cage structure and the ring structure will be formed, the former in a direct process, the latter via a negative barrier $(-9 \mathrm{~kJ} / \mathrm{mol}$, Fig. 13).

However, at the chosen experimental conditions, $\mathrm{V}_{3} \mathrm{O}_{8}{ }^{+}$ binds a second Ar atom (Fig. 13). The total binding energies for two Ar atoms are very similar for all three structures, between 40 and $42 \mathrm{~kJ} / \mathrm{mol}$ (Table 5), which results in a larger incremental binding for the second $\mathrm{Ar}$ atom for the cage structure $(19 \mathrm{~kJ} / \mathrm{mol})$ compared to the ring $(14 \mathrm{~kJ} / \mathrm{mol})$ and the transition structure $(11 \mathrm{~kJ} / \mathrm{mol})$. This makes the cage isomer of the $\mathrm{Ar}_{2}$ complex more stable than the ring isomer, and brings the transition structure of the $\mathrm{Ar}_{2}$ complex at about the same energy as the ring structure of the Ar complex (plus the second Ar atom at large distance), see Fig. 13. Hence, any ring $\mathrm{Ar}$ complexes formed can convert back into the more stable cage $\mathrm{Ar}_{2}$ complexes, and we expect that the $\eta^{2}$-peroxo cage structure of the $\mathrm{Ar}_{2}$ complex is predominantly formed in agreement with the IRPD spectra shown in Fig. 10.

Comparison of calculated and observed spectra (Fig. 9) has produced evidence that only the $\eta^{2}$-peroxo cage structure 
which is the lowest energy isomer is present as a bare ion. This means that on Ar addition only structures will be observed that can be formed from these bare ion structures. The $\eta^{2}$-peroxo cage structure survives on Ar addition, and the conversion of the bare $\eta^{2}$-peroxo cage into the $\eta^{2}$-peroxo ring structure of the complex is easily possible (negative barrier) as discussed above. The $\mu-\left(\eta^{1}-\eta^{1}\right)$-peroxo ring isomers are the lowest energy structures of the $\mathrm{V}_{3} \mathrm{O}_{8}{ }^{+}$. Ar complex (isomer a is the global minimum), but it will not be formed because the corresponding bare ion structure is not present in the ion trap, and isomerization of the $\eta^{2}$-peroxo cage structures will not occur because it requires migration of an $\mathrm{O}$ atom from the $\eta^{2}$-peroxo group into a $\mathrm{V}-\mathrm{O}-\mathrm{V}$ bridge forming a $\mathrm{V}-\mathrm{O}-\mathrm{O}-\mathrm{V}$ bridge. The barrier for such a process is so high (of the order of the energy of dissociation into $\mathrm{V}_{3} \mathrm{O}_{7}{ }^{+}+\mathrm{O}, 295 \mathrm{~kJ} / \mathrm{mol}$ ) that it is far from being compensated by the energy released on adding an Ar atom.

\section{Summary and conclusions}

The structure of trinuclear vanadium oxide clusters delicately depends on their oxygen content and their environment. $\mathrm{V}_{3} \mathrm{O}_{7}{ }^{+}$, in which all atoms are either fully oxidized (vanadium) or reduced (oxygen), forms a stable cage structure of $\mathrm{C}_{3 \mathrm{v}}$ symmetry. Whereas the cage motif remains the global minimum energy structure in $\mathrm{V}_{3} \mathrm{O}_{8}{ }^{+}$, removal of an oxygen atom from $\mathrm{V}_{3} \mathrm{O}_{7}{ }^{+}$results in a destabilization of this structure with respect to the other isomers, and the chain and ring motifs become more favourable in $\mathrm{V}_{3} \mathrm{O}_{6}{ }^{+}$. The cage motif has also been identified as the most stable isomer for the isovalent $\mathrm{Nb}_{3} \mathrm{O}_{8}{ }^{+}$, which exhibits a similar richness in energetically close-lying isomers. ${ }^{17}$ Due to overlapping fragmentation channels resulting from the lack of mass-selection of the parent ions from the molecular beam prior to IR radiation the vibrational spectra of $\mathrm{Nb}_{3} \mathrm{O}_{6}{ }^{+}$and $\mathrm{Nb}_{3} \mathrm{O}_{7}{ }^{+}$could not be assigned in those experiments, highlighting the increased sensitivity of the present ion trap tandem-mass spectrometer approach.

The addition of rare gas atoms can remarkably change the relative energies of different isomers, mainly due to the rather strong polarization of the rare gas atom(s) by a localized and accessible positive charge. For $\mathrm{V}_{3} \mathrm{O}_{6}{ }^{+}$we have shown that by addition of $\mathrm{He}$ atoms that isomer (chain) can be discriminated from a mixture that binds more than two $\mathrm{He}$ atoms with almost the same energy per $\mathrm{He}$ atom.

Particularly noteworthy is the stabilization of the ring isomers over the cage isomers by addition of one $\mathrm{Ar}$ atom in $\mathrm{V}_{3} \mathrm{O}_{7,8}{ }^{+} \cdot \mathrm{Ar}$, and the restoration of the cage stability in $\mathrm{V}_{3} \mathrm{O}_{8}{ }^{+} \cdot \mathrm{Ar}_{2}$. While it is known that heavier rare gas atoms like Ar will shift vibrational frequencies and modulate intensities, for example in complexes with metal containing clusters, ${ }^{44}$ such dramatic effects on cluster energies as described here to our knowledge are rarely observed.

Given the fact that the energy differences between different isomers are at the accuracy limits of DFT calculations, we also conclude that a firm determination of the most stable isomer structure of transition metal oxides is only possible by combining information from global structure optimization, quantum chemical calculations at different levels and IRPD spectroscopy.

\section{Acknowledgements}

This work has been supported by German Research Foundation within SFB 546.

\section{Notes and references}

1 B. M. Weckhuysen and D. E. Keller, Catal. Today, 2003, 78, 25-46.

2 Y. S. Hu, X. Liu, J. O. Müller, R. Schlögl, J. Maier and D. S. Su, Angew. Chem., Int. Ed., 2009, 48, 210-214; F. Stavale, C. A. Achete and H. Niehus, Surf. Sci., 2007, 601, 4881-4887.

3 N. Magg, B. Immaraporn, J. B. Giorgi, T. Schroeder, M. Bäumer, J. Döbler, Z. L. Wu, E. Kondratenko, M. Cherian, M. Baerns, P. C. Stair, J. Sauer and H.-J. Freund, J. Catal., 2004, 226, 88-100.

4 D. K. Böhme and H. Schwarz, Angew. Chem., Int. Ed., 2005, 44, 2336-2354.

5 S. F. Vyboishchikov and J. Sauer, J. Phys. Chem. A, 2001, 105, $8588-8598$.

6 J. Sauer and J. Döbler, Dalton Trans., 2004, 3116-3121.

7 K. R. Asmis, G. Santambrogio, M. Brümmer and J. Sauer, Angew. Chem., Int. Ed., 2005, 44, 3122-3125.

8 K. R Asmis, Phys. Chem. Chem. Phys., 2012, DOI: 10.1039/ $\mathrm{C} 2 \mathrm{CP} 40762 \mathrm{~K}$

9 H. J. Zhai, B. Kiran, L. F. Cui, X. Li, D. A. Dixon and L. S. Wang, J. Am. Chem. Soc., 2004, 126, 16134-16141; H. J. Zhai and L.-S. Wang, J. Chem. Phys., 2002, 117, 7882-7888; H. J. Zhai, J. Döbler, J. Sauer and L. S. Wang, J. Am. Chem. Soc., 2007, 129, 13270-13276.

10 G. von Helden, A. Kirilyuk, D. van Heijnsbergen, B. Sartakov, M. A. Duncan and G. Meijer, Chem. Phys., 2000, 262, 31-39.

11 K. R. Asmis, M. Brümmer, C. Kaposta, G. Santambrogio, G. von Helden, G. Meijer, K. Rademann and L. Wöste, Phys. Chem. Chem. Phys., 2002, 4, 1101-1104.

12 K. R. Asmis, A. Fielicke, G. von Helden and G. Meijer, in The Chemical Physics of Solid Surfaces. Atomic Clusters: From Gas Phase to Deposited, ed. D. P. Woodruff, Elsevier, Amsterdam, 2007, vol. 12, pp. 327-375.

13 M. Brümmer, C. Kaposta, G. Santambrogio and K. R. Asmis, J. Chem. Phys., 2003, 119, 12700-12703.

14 K. R. Asmis, G. Meijer, M. Brümmer, C. Kaposta, G. Santambrogio, L. Wöste and J. Sauer, J. Chem. Phys., 2004, 120, 6461-6470; A. Fielicke, R. Mitrić, G. Meijer, V. Bonačić-Koutecký and G. von Helden, J. Am. Chem. Soc., 2003, 125, 15716-15717.

15 G. Santambrogio, M. Brümmer, L. Wöste, J. Döbler, M. Sierka, J. Sauer, G. Meijer and K. R. Asmis, Phys. Chem. Chem. Phys., 2008, 10, 3992-4005.

16 K. R. Asmis and J. Sauer, Mass Spectrom. Rev., 2007, 26, 542-562; K. R. Asmis and J. Sauer, Mass Spectrom. Rev., 2008, 27, 205.

17 A. Fielicke, G. Meijer and G. von Helden, J. Am. Chem. Soc., 2003, 125, 3659-3667.

18 A. Fielicke, G. Meijer and G. von Helden, Eur. Phys. J. D, 2003, 24, 69-72.

19 M. Sierka, Prog. Surf. Sci., 2010, 85, 398-434.

20 S. Feyel, D. Schröder, X. Rozanska, J. Sauer and H. Schwarz, Angew. Chem., Int. Ed., 2006, 45, 4677-4681.

21 X. Rozanska and J. Sauer, J. Phys. Chem. A, 2009, 113, 11586-11594.

22 X. Rozanska, E. V. Kondratenko and J. Sauer, J. Catal., 2008, 256, 84-94.

23 M. Okumura, L. I. Yeh, J. D. Myers and Y. T. Lee, J. Chem. Phys., 1986, 85, 2328-2329.

24 M. Sierka, J. Döbler, J. Sauer, G. Santambrogio, M. Brümmer, L. Wöste, E. Janssens, G. Meijer and K. R. Asmis, Angew. Chem., Int. Ed., 2007, 46, 3372-3375; M. Sierka, J. Döbler, J. Sauer, G. Santambrogio, M. Brümmer, L. Wöste, E. Janssens, G. Meijer and K. R. Asmis, Angew. Chem., 2007, 119, 3437-3440.

25 D. M. Deaven and K. M. Ho, Phys. Rev. Lett., 1995, 75, 288-291.

26 G. Santambrogio, E. Janssens, S. Li, T. Siebert, G. Meijer, K. R. Asmis, J. Döbler, M. Sierka and J. Sauer, J. Am. Chem. Soc., 2008, 130, 15143-15149.

27 D. Oepts, A. F. G. van der Meer and P. W. van Amersfoort, Infrared Phys. Technol., 1995, 36, 297-308.

28 D. J. Goebbert, E. Garand, T. Wende, R. Bergmann, G. Meijer, K. R. Asmis and D. M. Neumark, J. Phys. Chem. A, 2009, 113, 7584-7592; D. J. Goebbert, G. Meijer and K. R. Asmis, AIP Conf. Proc., 2009, 1104, 22-29. 
29 D. J. Goebbert, T. Wende, R. Bergmann, G. Meijer and K. R. Asmis, J. Phys. Chem. A, 2009, 113, 5874-5880.

30 TURBOMOLE V6.3.1 2011, a development of University of Karlsruhe and Forschungszentrum Karlsruhe $\mathrm{GmbH}$, 1989-2007, s. TURBOMOLE GmbH, see http://www.turbomole. com; R. Ahlrichs, M. Bär, M. Häser, H. Horn and C. Kölmel, Chem. Phys. Lett., 1989, 162, 165-169; K. Eichkorn, O. Treutler, H. Öm, M. Häser and R. Ahlrichs, Chem. Phys. Lett., 1995, 242, 652-660; O. Treutler and R. Ahlrichs, J. Chem. Phys., 1995, 102, 346-354.

31 A. D. Becke, Phys. Rev. A, 1988, 38, 3098-3100; A. D. Becke, J. Chem. Phys., 1993, 98, 5648-5652; C. Lee, W. Yang and R. G. Parr, Phys. Rev. B: Condens. Matter Mater. Phys., 1988, 37, 785-789.

32 A. Schäfer, C. Huber and R. Ahlrichs, J. Chem. Phys., 1994, 100, $5829-5835$.

33 A. J. Wachters, J. Chem. Phys., 1970, 52, 1033-1036.

34 P. Deglmann, F. Furche and R. Ahlrichs, Chem. Phys. Lett., 2002, 362, 511-518.

35 A. P. Scott and L. Radom, J. Chem. Phys., 1996, 100, 16502-16513; M. D. Halls, J. Velkovski and H. B. Schlegel, Theor. Chem. Acc., 2001, 105, 413-421.

36 K. R. Asmis, G. Meijer, M. Brümmer, C. Kaposta, G. Santambrogio, L. Wöste and J. Sauer, J. Chem. Phys., 2004, 120, 6461-6470.
37 S. Grimme, J. Comput. Chem., 2006, 27, 1787-1799.

38 C. Hättig and F. Weigend, J. Chem. Phys., 2000, 113, 5154.

39 F. Weigend and R. Ahlrichs, Phys. Chem. Chem. Phys., 2005, 7, 3297-3305.

40 H.-J. Werner, P. J. Knowles, R. Lindh, F. R. Manby, M. Schütz, P. Celani, T. Korona, G. Rauhut, R. D. Amos, A. Bernhardsson, A. Berning, D. L. Cooper, M. J. O. Deegan, A. J. Dobbyn, F. Eckert, C. Hampel, G. Hetzer, A. W. Lloyd, S. J. McNicholas, W. Meyer, M. E. Mura, A. Nicklaß, P. Palmieri, R. Pitzer, U. Schumann, H. Stoll, A. J. Stone, R. Tarroni and T. Thorsteinsson, MOLPRO, version 2006.1, a package of ab initio programs, see www.molpro.net.

41 J. Oomens, A. G. G. M. Tielens, B. Sartakov, G. von Helden and G. Meijer, Astrophys. J., 2003, 591, 968-985; V. N. Bagratashvili, V. S. Letokhov, A. A. Makarov and E. A. Ryabov, Multiple Photon Infrared Laser Photophysics and Photochemistry, Harwood Academic Publishers, GmbH, Amsterdam, 1985.

42 M. Calatayud, J. Andrés and A. Beltrán, J. Phys. Chem. A, 2001, 105, 9760-9775.

43 N. A. Deskins and M. Dupuis, Phys. Rev. B: Condens. Matter Mater. Phys., 2007, 75, 195212; N. A. Deskins, R. Rousseau and M. Dupuis, J. Phys. Chem. C, 2009, 113, 14583-14586.

44 R. Gehrke, P. Gruene, A. Fielicke, G. Meijer and K. Reuter, J. Chem. Phys., 2009, 130, 1-11. 